$$
\begin{gathered}
\text { Universidade de São Paulo } \\
\text { Instituto de Psicologia }
\end{gathered}
$$

Programa de Pós-Graduação em Neurociências e Comportamento

Viviani Mantovani Amador

Estudo genético dos pigmentos visuais em primatas do Novo Mundo

São Paulo 


\section{Estudo genético dos pigmentos visuais em primatas do Novo Mundo}

\section{(Versão corrigida)}

Dissertação apresentada ao Programa de Neurociências e Comportamento do Instituto de Psicologia da Universidade de São Paulo, como parte dos requisitos para obtenção do grau de Mestre em Ciências.

Área de concentração:

Neurociências e Comportamento

Orientadora: Prof ${ }^{\mathrm{a}}$. Dr ${ }^{\mathrm{a}}$. Daniela Maria Oliveira Bonci

São Paulo 
AUTORIZO A REPRODUÇÃO E DIVULGAÇÃO TOTAL OU PARCIAL DESTE TRABALHO, POR QUALQUER MEIO CONVENCIONAL OU ELETRÔNICO, PARA FINS DE ESTUDO E PESQUISA, DESDE QUE CITADA A FONTE.

Catalogação na publicação

Biblioteca Dante Moreira Leite

Instituto de Psicologia da Universidade de São Paulo

Mantovani, Viviani Amador.

Estudo genético dos pigmentos visuais em primatas do Novo Mundo / Viviani Mantovani Amador; orientadora Daniela Maria Oliveira Bonci. -- São Paulo, 2015.

$82 \mathrm{f}$.

Dissertação (Mestrado - Programa de Pós-Graduação em Psicologia. Área de Concentração: Neurociências e Comportamento) Instituto de Psicologia da Universidade de São Paulo.

1. Visão de Cores 2. Fotorreceptores 3. Opsinas 4. Primatas do Novo Mundo I. Título. 
Nome: Viviani Mantovani Amador

Título: Estudo genético dos pigmentos visuais em primatas do Novo Mundo

Dissertação apresentada ao Instituto de Psicologia da Universidade de São Paulo para obtenção do título de Mestre em Ciências.

\section{Aprovada em:}

\section{Banca Examinadora}

Prof. Dr.

Instituição: Assinatura:

Prof. Dr.

Instituição: Assinatura:

Prof. Dr.

Instituição: Assinatura:

Prof. Dr.

Instituição: Assinatura:

Prof. Dr.

Instituição: Assinatura: 


\section{Agradecimentos}

Agradeço à minha orientadora, Professora Dra. Daniela Bonci, pela confiança, aconselhamento e por todo ajuda e ensinamentos ao longo do mestrado.

À Einat Hauzman, pela presença amiga e profissional, por estar sempre disposta a ajudar, ensinar e cuidar do sequenciamento da biologia molecular.

Ao CNPq, pela concessão da bolsa de mestrado e a FAPESP pelo apoio financeiro.

Aos pesquisadores Maurício Talebi da UNIFESP, Paulo Goulart e Olavo Galvão da UFPA, Juliana Soares, Mario Fiorani e Ricardo Gattass da UFRJ pelo fornecimento das amostras de material genético para a realização dessa pesquisa.

Ao Instituto Israelita de Ensino e Pesquisa (IIEP) do Hospital Israelita Albert Einstein, por aceitar a realização deste projeto e permitir a utilização dos equipamentos.

Ao amigo de laboratório Felipe Galante pela ajuda e colaboração no dia a dia do laboratório.

A todos do Labvis, professores, alunos e funcionários.

Ao meu pai que sempre me incentivou a estudar, pelo apoio e aconselhamento ao longo desses anos.

À minha mãe por todo amor, presença, ajuda e dedicação.

E agradeço especialmente ao meu marido Raphael pelo incentivo, apoio e pelo companheirismo de todos os dias. Obrigada por tudo amor! 
Apoio Financeiro

Bolsa de mestrado CNPq 132226/2014-6

Projeto Temático FAPESP (2008/58731-2) 


\section{Sumário}

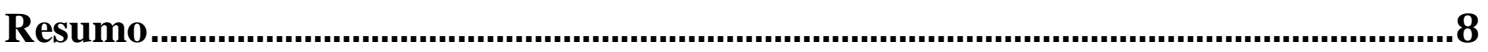

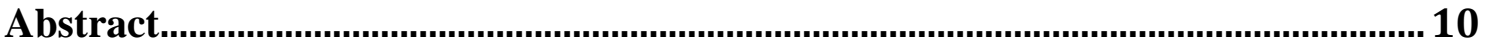

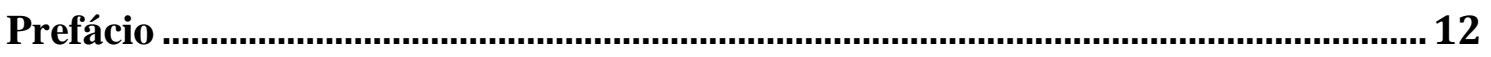

1. Introdução

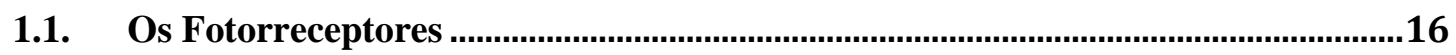

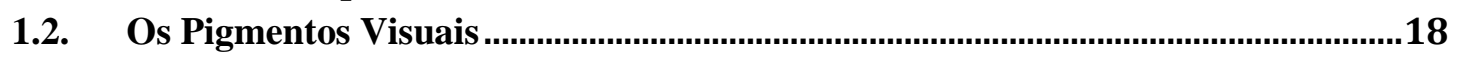

1.3. O Processamento da cor .....................................................................................22

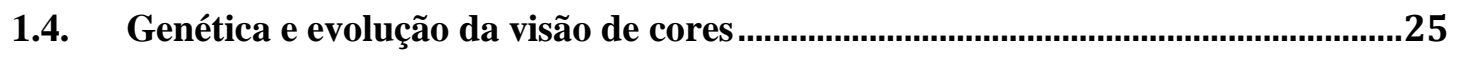

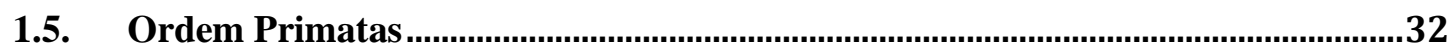

1.5.1. Primatas do Novo Mundo: Classificação e Características ...............................................33



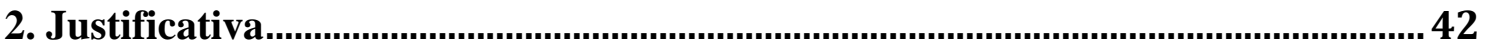

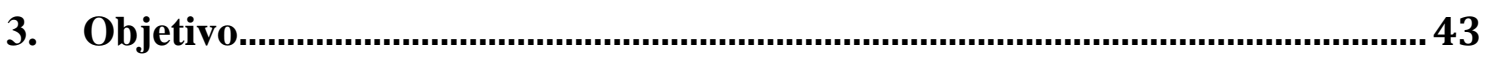

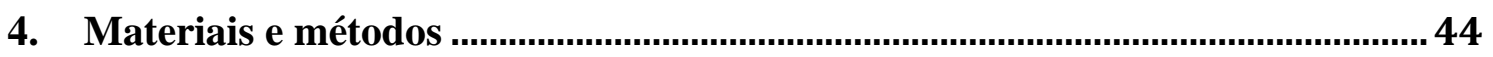

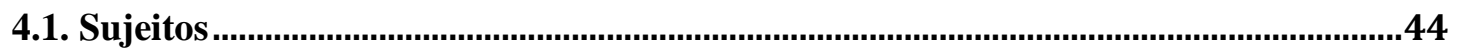

4.1.1. Grupo experimental (Gene SWS) ........................................................................ 44

4.1.2. Grupo experimental (Gene LWS/MWS) .............................................................. 45

4.2. Análise Genética...................................................................................................45

4.3. Determinação da curva de absorção espectral das opsinas .....................................47

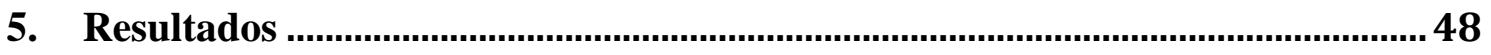

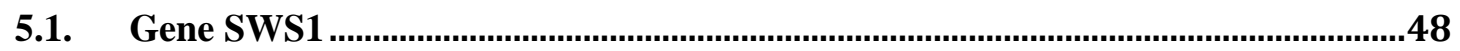

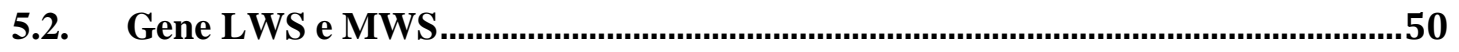



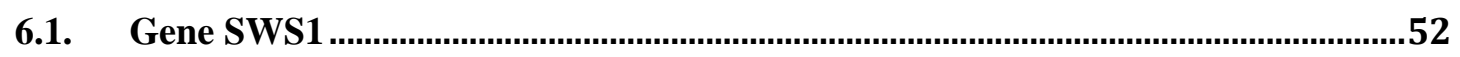

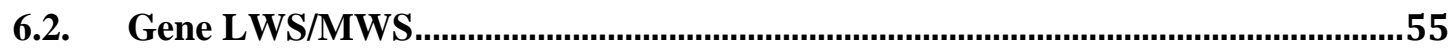

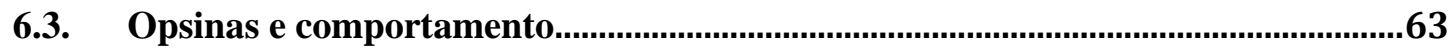

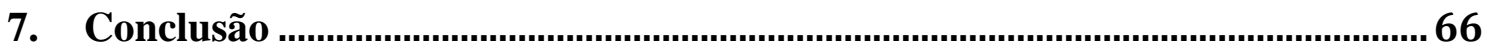



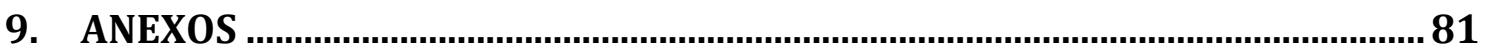




\section{Resumo}

Mantovani, V. A. (2015). Estudo genético dos pigmentos visuais em primatas do Novo Mundo. Dissertação de Mestrado, Instituto de Psicologia, Universidade de São Paulo, São Paulo.

A visão de cores em vertebrados necessita de pelo menos duas classes de cones, (fotorreceptores presentes na retina) e a existência de um substrato neural para que os fótons de luz sejam comparados, processados e posteriormente resultar na sensação da cor. Primatas do Velho Mundo, incluindo humanos, apresentam visão de cor tricromata, enquanto que primatas do Novo Mundo apresentam um polimorfismo nos genes dos pigmentos visuais e, entre os primatas, são os únicos que podem apresentar indivíduos com visão dicromata ou tricromata. O polimorfismo encontrado em primatas do Novo Mundo ocorre devido à variabilidade dos genes que expressam as opsinas responsáveis por absorver comprimentos de onda médios ou longos. Os estudos genéticos das opsinas são essenciais para compreensão do processamento e da sensação de cores nesses animais, e podem ajudar a entender a evolução da visão de cores nos Primatas. O objetivo deste trabalho é caracterizar a diversidade dos pigmentos visuais (LWS/MWS e SWS1) das espécies de primatas do Novo Mundo através de análises genéticas e descrever a sequência de aminoácidos observados para estimar o pico de sensibilidade espectral das opsinas. Foram coletadas amostras de sangue, fezes e/ou pelo de seis gêneros de primatas provenientes de diferentes regiões do Brasil (Pará, Rio de Janeiro, Rio Grande do Norte e São Paulo) e pertencentes às espécies Cebus apella, Callithrix jacchus, Alouatta clamitans, Alouatta caraya, Lagothrix lagothricha, Ateles belzebuth e Brachyteles arachnoides e posteriormente foram analisados os genes que expressam as opsinas nesses indivíduos. As sequências de aminoácidos encontradas nas posições importantes do gene SWS1 $(52,86,93,114$ e 118) foram diferentes para algumas 
espécies. No gene SWS1 as espécies C. apella, L. lagotricha, A. belzebuth e $B$. arachnoides apresentam a sequência de aminoácidos LLPAT e as espécies C. jacchus, A. caraya e A. clamitans apresentaram a sequência de aminoácidos LLPGT. Foi descoberto que variações de aminoácidos na posição 50 do gene SWS1 em primatas do Novo Mundo podem ser importantes na determinação do pico de absorção espectral dos pigmentos expressos por este gene. Os genes LWS e MWS de indivíduos da espécie $C$. jacchus foram estudados e os aminoácidos localizados nas posições 180, 277 e 285 das opsinas foram identificados. Os resultados dos alelos encontrados nesses grupos tiveram cinco combinações diferentes (SFT, SYA, SYT, AYA e AYT), os alelos AYA e SYA foram descritos pela primeira vez neste grupo e a partir do resultado genético foi inferido o pico de absorção espectral da opsina. Este trabalho preencheu algumas lacunas da bibliografia e trouxe novas informações a respeito da diversidade genética dos pigmentos visuais em primatas do Novo Mundo.

Palavras-chave: Visão de Cores, Fotorreceptores, Opsinas, primatas do Novo Mundo. 


\begin{abstract}
Mantovani, V. A. (2015). Genetic study of visual pigments in the New World monkeys. Dissertação de Mestrado, Instituto de Psicologia, Universidade de São Paulo, São Paulo.
\end{abstract}

Color vision in vertebrates requires the presence of at least two different classes of cones in the retina, and a neural substrate capable to compare the activation of the different photoreceptors, which ultimately leads to color perception. Old World Monkeys (OWM), including humans, have trichromatic color vision, whereas New World Monkeys (NWM) have visual pigment genes polymorphism and among primates, are the only group with dichromatic or trichromatic individuals in the same species. This polymorphism in NWM occurs due to the variability of genes that express the opsins responsible for absorbing medium or long wavelengths. The genetic studies of color vision are fundamental for the comprehension of color perception in these animals and it could help to understand the color vision evolution in Primates. The aim of this work is to characterize the visual pigment diversity (LWS/MWS and SWS1) in NWM species by genetic analysis and estimate the opsin spectral absorption peak, based on the amino acid sequence. Blood, feces and hair were collected from six primate genres from different regions of Brazil (Pará, Rio de Janeiro, Rio Grande do Norte and São Paulo): Cebus apella, Callithrix jacchus, Alouatta clamitans, Alouatta caraya, Lagothrix lagothricha, Ateles belzebuth and Brachyteles arachnoides. The amino acid sequences found in important positions of the SWS1 gene (52, 86, 93, 114 and 118) were different among some species. In C. apella, L. lagotricha, A. belzebuth and $B$. arachnoides was found the amino acid sequence LLPAT. In $C$. jacchus, $A$. caraya and A. clamitans the amino acid sequence was LLPGT. It was observed in previous studies that residue 50 of the SWS1 gene in the New World primates is 
important to determining the spectral absorption peak of the visual pigments expressed by this gene. The LWS and MWS genes of $C$. jacchus have been studied and the amino acids located at positions 180, 277 and 285 have been identified. Five different combinations were found among the individuals analyzed: SFT, SYA, SYT, AYA and AYT. Two alleles, AYA and SYA, were described for the first time in this species. The present study filled some gaps in the literature and brought new information on the genetic diversity of visual pigments in New World primates.

Keywords: Color Vision, Photoreceptors, Opsins, New World monkeys. 


\section{Prefácio}

Nesta dissertação também serão mencionados os trabalhos realizados pela Dra. Daniela Maria Oliveira Bonci, correspondente aos genes LWS e MWS de seis espécies de primatas do Novo Mundo estudadas neste trabalho, com exceção da espécie Callithrix jacchus. Dentre essas espécies que serão citadas, Cebus apella teve os resultados das análises do gene LWS e MWS publicado em 2012 em Tese de Doutorado e os resultados das demais espécies (Brachyteles arachnoides, Lagothrix lagotricha, Alouatta caraya, Alouatta clamitans e Ateles belzebuth) ainda não foram publicados. 


\section{Lista de Figuras}

Figura 1. Micrografia eletrônica de bastonetes e cones de retina de primata. Imagem adaptada de Ralph C. Eagle (www.webvision.med.utah,edu).

Figura 2. Representação de fotorreceptores da retina de vertebrados. Modificado de Burns \& Lamb, 2003.

Figura 3. Diagrama esquemático do segmento externo de um fotorreceptor (bastonete) e a opsina inserida na membrana plasmática. Modificado de: http://webvision.med.utah.edu/

Figura 4. Estrutura tri-dimensional da rodopsina. Os sete domínios transmembrânicos estão ilustrados em amarelo. O retinal está identificado em vermelho. Fonte: http://acces.ens-lyon.fr/biotic/evolut/mecanismes/opsines/html/structureopsines.htm

Figura 5. Curva de absorção espectral das três classes de fotopigmentos encontrados nos cones da retina de humanos com visão de cores tricromata. Os comprimentos de onda de máxima absorção dos cones $\mathrm{S}, \mathrm{M}$ e $\mathrm{L}$ estão indicados entre parênteses. As três classes de cones também são encontradas em primatas do Velho Mundo, alguns primatas do Novo Mundo e em hominídeos com pequenas variações no pico de absorção entre as espécies. Modificado de Deeb \& Motulsky (2005).

Figura 6. Esquema comparativo da sequência de aminoácidos dos diferentes tipos de pigmentos visuais encontrados em primatas do Novo Mundo e humanos. Os círculos coloridos representam os aminoácidos diferentes da estrutura molecular dos pigmentos e os círculos em branco representam os aminoácidos comuns aos dois pigmentos (http://www.handprint.com/HP/WCL/color1.html\#conechemistry).

Figura 7. Esquema da organização celular da retina. Modificado de Kolb, 2003.

Figura 8. Representação de um campo receptivo de célula ganglionar com oponência cromática. Modificado de Bear, Connors e Paradiso, 2002.

Figura 9. Classes de bastonetes e cones mantidas e perdidas em mamíferos. A origem do L e M variantes do gene de LWS por duplicação de genes em primatas do Velho Mundo, Hominoidea e em primatas do Novo Mundo é mostrado. Modificado de Hunt, Carvalho, Cowing \& Davies (2009).

Figura 10. Cinco grupos de genes que expressam os pigmentos visuais encontrados na retina de vertebrados. O gene Rh1 está associado a pigmentos encontrados em bastonetes e os outros quatro genes a pigmentos encontrados em cones. A extensão das linhas horizontais indica a faixa de localização dos picos espectrais dos pigmentos expressos por cada grupo. Modificado de Jacobs (2008).

Figura 11. Classificação parcial da ordem Primata, incluindo a divisão das subordens Strepsirhini e Haplorhini. Modificado de Lewis et al. (2012).

Figura 12. Árvore filogenética de Primatas do Novo Mundo obtida por máxima parcimônia (MP). Comprimentos dos ramos e desvios-padrão foram estimados com 
base no método dos mínimos quadrados. Tempos de divergência foram estimados usando a estratégia de relógio molecular local. Valores de MP Bootstrap nos nós foram obtidas em 1000 repetições. Estrelas em nós significam BS (Bootstrapping) de 99$100 \%$. O índice de comprimento e consistência da árvore MP foi 2,855 e 0,83, respectivamente. Modificado de Schneider (2000).

Figura. 13. Distribuição geográfica dos primatas do Novo Mundo atuais. Modificado de Lewis et al. (2012).

Figura 14. Curvas de sensibilidade espectrais previstas a partir das sequências de aminoácidos dos pigmentos S, L e M para os cones de Alouatta, Ateles, Brachyteles, Lagothrix, Callithrix e Cebus. Gráficos elaborados pelo Dr. Balázs Vince Nagy baseado em Stockman \& Sharpe (2000). 


\section{Lista de Tabelas}

Tabela 1. Resumo dos trabalhos publicados que descrevem o pico de sensibilidade espectral das opsinas em algumas espécies de primatas do Novo Mundo. Modificado de Bonci et al., 2013.

Tabela 2. Principais aminoácidos responsáveis pela diferenciação do ultravioleta (UV) e do violeta (VS) e absorção espectral da opsina expressa pelo gene SWS1 de diferentes espécies de primatas do Novo Mundo.

Tabela 3. Descrição de características gerais apresentadas nos gêneros de primatas do Novo Mundo analisados neste trabalho.

Tabela 4. Espécies de primatas do Novo Mundo estudadas no presente trabalho.

Tabela 5. Descrição dos Primers e temperatura de anelamento destes ao DNA.

Tabela 6. Descrição dos aminoácidos encontrados em diferentes sítios do gene SWS1, nas diferentes espécies de primatas do Novo Mundo e o pico de absorção espectral inferido a partir das sequências de aminoácidos.

Tabela 7. Posições dos aminoácidos encontrados em indivíduos da espécie Callithrix jacchus

Tabela 8. Principais aminoácidos responsáveis pela diferenciação do ultravioleta (UV) e do violeta (VS) e absorção espectral da opsina expressa pelo gene SWS1 de diferentes espécies de primatas do Novo Mundo, Velho Mundo e humanos.

Tabela 9. Posições dos aminoácidos encontrados em indivíduos da espécie Cebus apella. Modificado de Bonci, 2012.

Tabela 10. Posições dos aminoácidos encontrados nas diferentes espécies estudadas da Família Atelidae.

Tabela 11. Diferentes alelos encontrados em algumas espécies de primatas do Novo Mundo.

Tabela 12. Resumo dos trabalhos publicados que descrevem o pico de sensibilidade espectral das opsinas em algumas espécies de Primatas do Novo Mundo incluindo o presente trabalho. 


\section{Introdução}

\subsection{Os Fotorreceptores}

Os mecanismos visuais são semelhantes entre os vertebrados, mas a faixa de cores que pode ser discriminada entre eles é distinta e depende de genes que expressam diferentes pigmentos visuais em diferentes fotorreceptores. Os objetos emitem ou refletem luz de diferentes comprimentos de ondas e os fotorreceptores sensíveis a esses comprimentos serão estimulados diferencialmente (Brown \& Wald, 1964; Vorobyev, 2004).

A visão depende de um grupo de células sensíveis à luz presentes na retina, células fotorreceptoras chamadas de bastonetes ou cones (Figura 1). Os bastonetes são mais sensíveis à luz e especializados em ambientes de baixa luminosidade (escotópicos). Os cones são menos sensíveis à luz e especializados em ambientes de alta luminosidade (fotópicos) contribuindo nestas condições para a visão de cores (Bowmaker, 1991).



Figura 1. Micrografia eletrônica de bastonetes e cones de retina de primata. Imagem adaptada de Ralph C. Eagle (www.webvision.med.utah,edu). 
As células fotorreceptoras são células alongadas, compostas por um segmento externo, localizado na superfície distal da retina neural, um segmento interno, localizado na parte mais proximal, o núcleo e o terminal sináptico (Figura 2) (Sterling, Freed \& Smith, 1988).

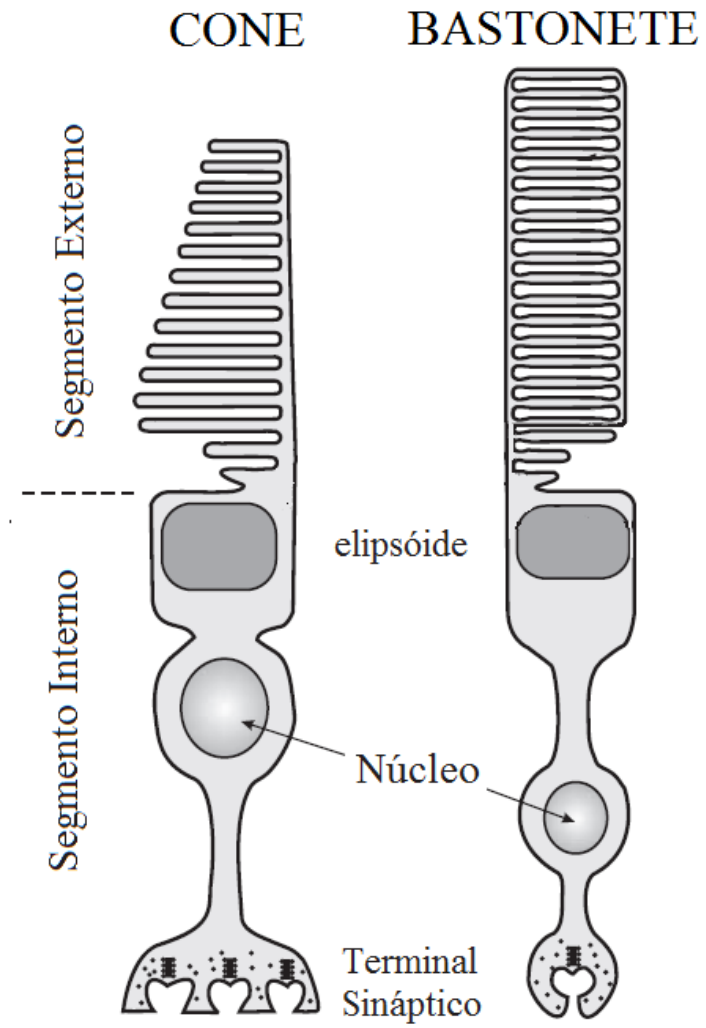

Figura 2. Representação de fotorreceptores da retina de vertebrados. Modificado de Burns \& Lamb, 2003.

O segmento interno é dividido em um elipsóide rico em mitocôndrias e o mielóide que contém retículo endoplasmático. O segmento externo é constituído por invaginações que formam discos membranosos, nos quais estão localizados os pigmentos visuais chamados opsinas ou rodopsinas (Figura 3). Esses pigmentos visuais absorvem fótons de luz e subsequentemente ativam os fotorreceptores nos quais ocorrerá a transdução da informação luminosa em sinal neural (Bowmaker, 1991). 


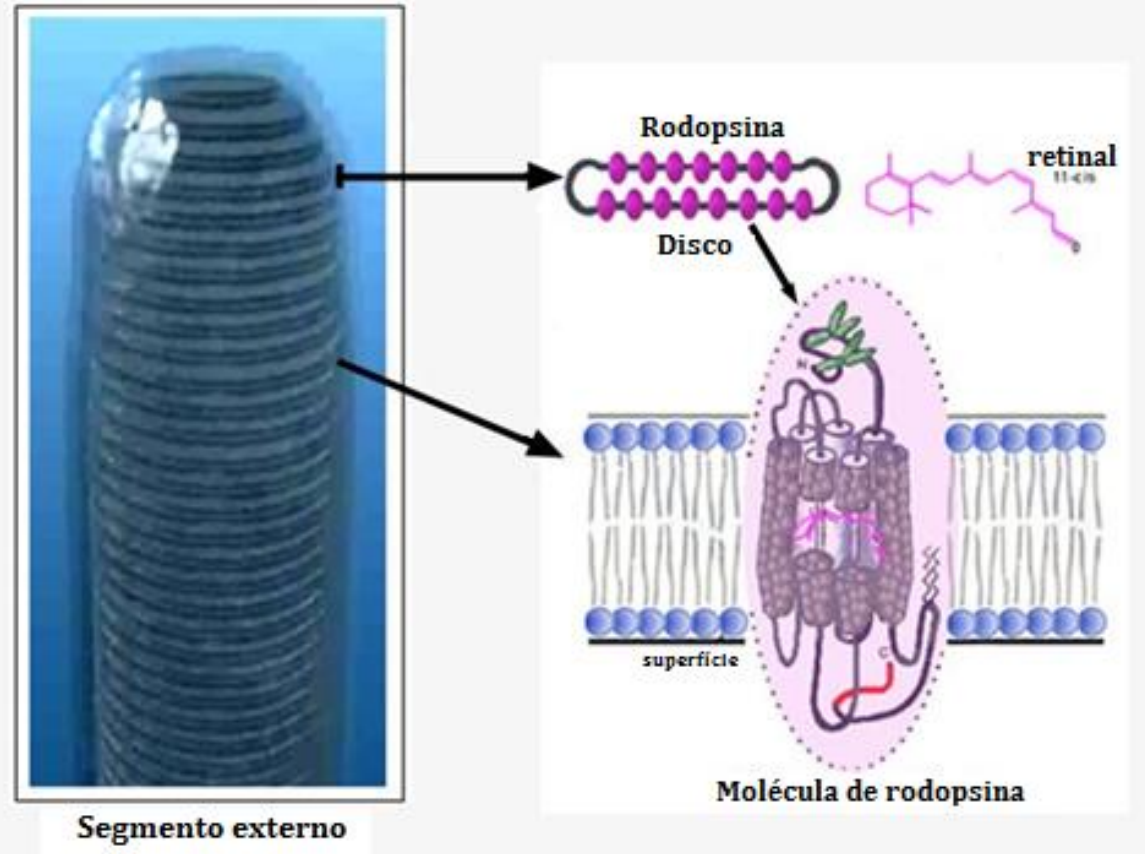

Figura 3. Diagrama esquemático do segmento externo de um fotorreceptor (bastonete) e a opsina inserida na membrana plasmática. Modificado de: http://webvision.med.utah.edu/

\subsection{Os Pigmentos Visuais}

Os pigmentos visuais são constituídos por um retinal, derivado da vitamina A, e uma proteína de membrana, a opsina ou rodopsina, formada por sete hélices transmembrânicas, sendo que metade da proteína está inserida na membrana plasmática. O retinal encontra-se acoplado ao resíduo lisina da proteína, na posição 296, através de uma ligação covalente (Figura 4) (Hargrave \& McDowell, 1992). 


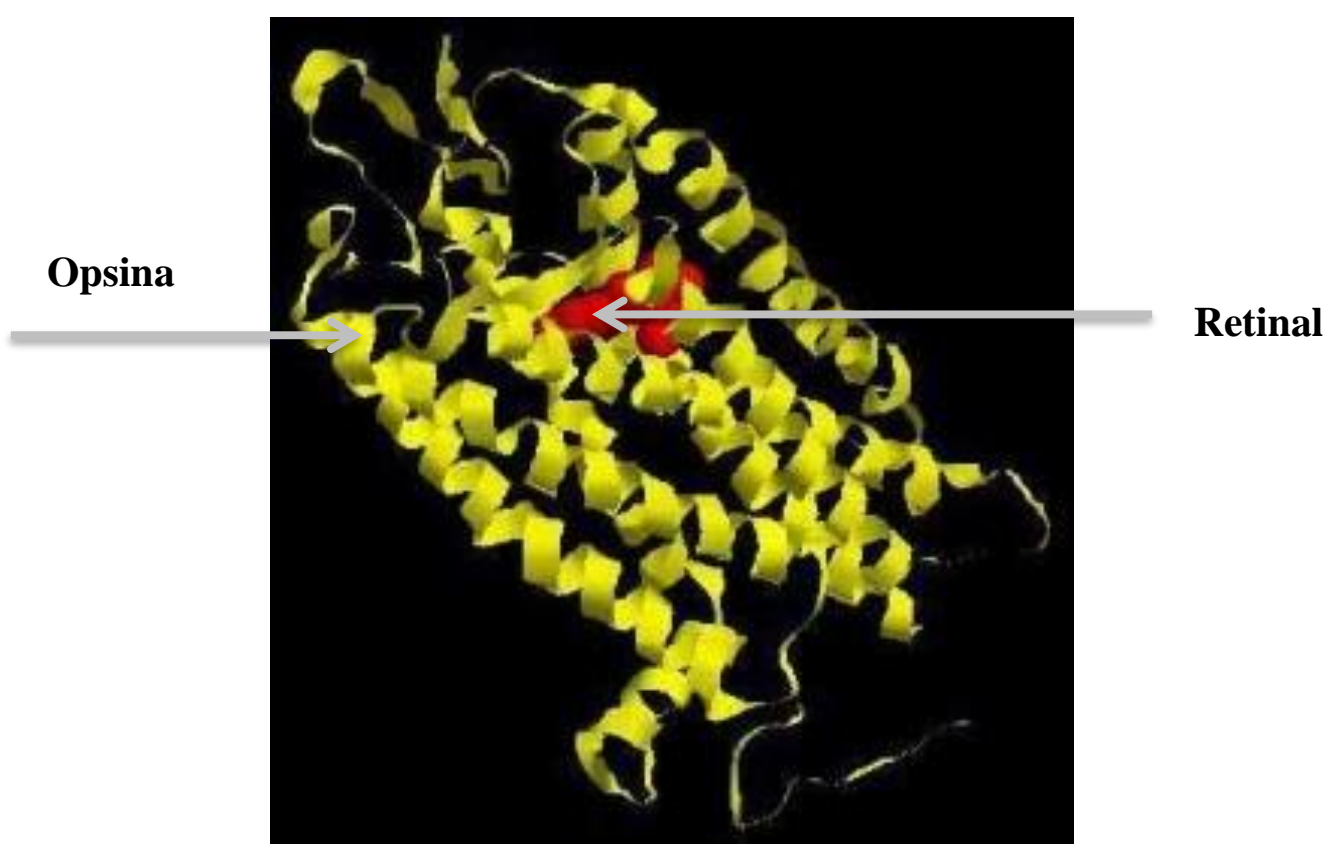

Figura 4. Estrutura tri-dimensional da rodopsina. Os sete domínios transmembrânicos estão ilustrados em amarelo. O retinal está identificado em vermelho. Fonte: http://acces.ens-lyon.fr/biotic/evolut/mecanismes/opsines/html/structureopsines.htm

As opsinas são formadas por aproximadamente 400 aminoácidos e os deslocamentos espectrais observados nos diferentes tipos de cones ocorrem devido a substituições de determinados aminoácidos presentes na opsina (Hunt et al., 1998). Um exemplo desses deslocamentos pode ser observado em humanos, espécie na qual é observada a presença de 3 tipos de cones, chamados de cone L, cone M e cone S. Estes cones expressam diferentes opsinas com pico de sensibilidade espectral em comprimentos de onda longo (L), médio (M) e curto (S), respectivamente (Figura 5). 


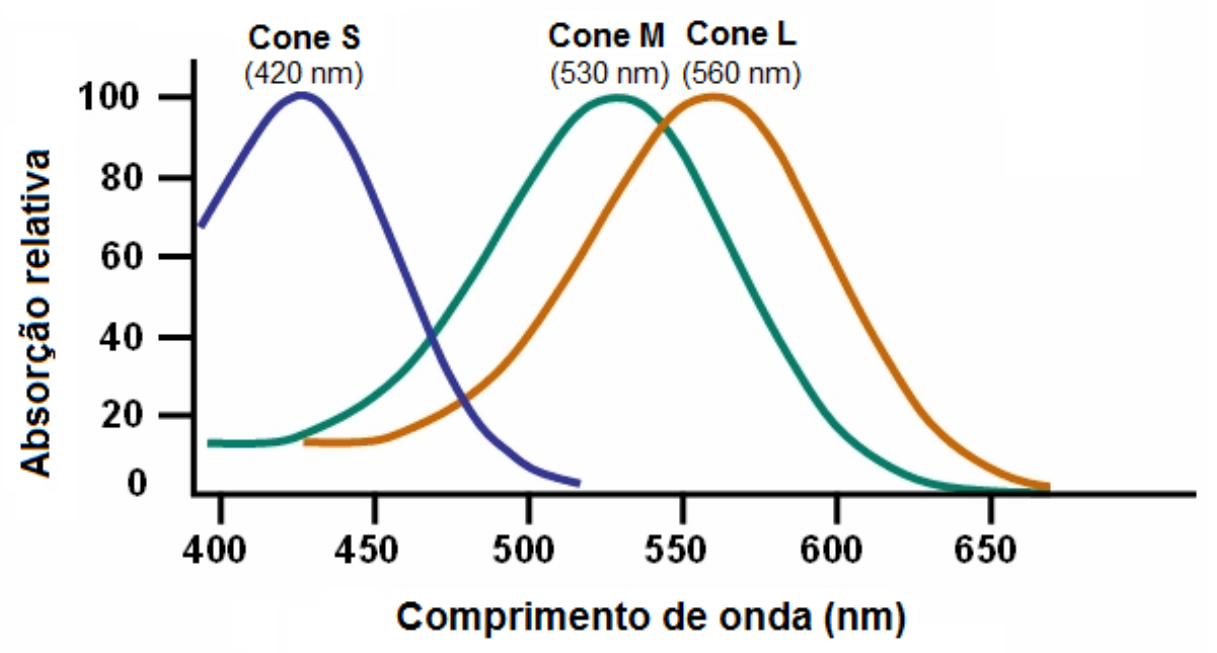

Figura 5. Curva de absorção espectral das três classes de fotopigmentos encontrados nos cones da retina de humanos com visão de cores tricromata. Os comprimentos de onda de máxima absorção dos cones $\mathrm{S}, \mathrm{M}$ e $\mathrm{L}$ estão indicados entre parênteses. As três classes de cones também são encontradas em primatas do Velho Mundo, alguns primatas do Novo Mundo e em hominídeos com pequenas variações no pico de absorção entre as espécies. Modificado de Deeb \& Motulsky (2005).

As opsinas dos cones L e M apresentam entre si, uma semelhança de $96 \%$ em sua sequência de aminoácidos, e a opsina do cone $\mathrm{S}$ possui $46 \%$ de homologia com relação às opsinas dos cones L e M (Figura 6). A variação na sequência de aminoácidos das opsinas é responsável pela distância entre as curvas de sensibilidade espectral dos fotorreceptores (Nathans, Thomas \& Hogness, 1986; Jacobs, 1996). 




Rodopsina $\rightarrow S$
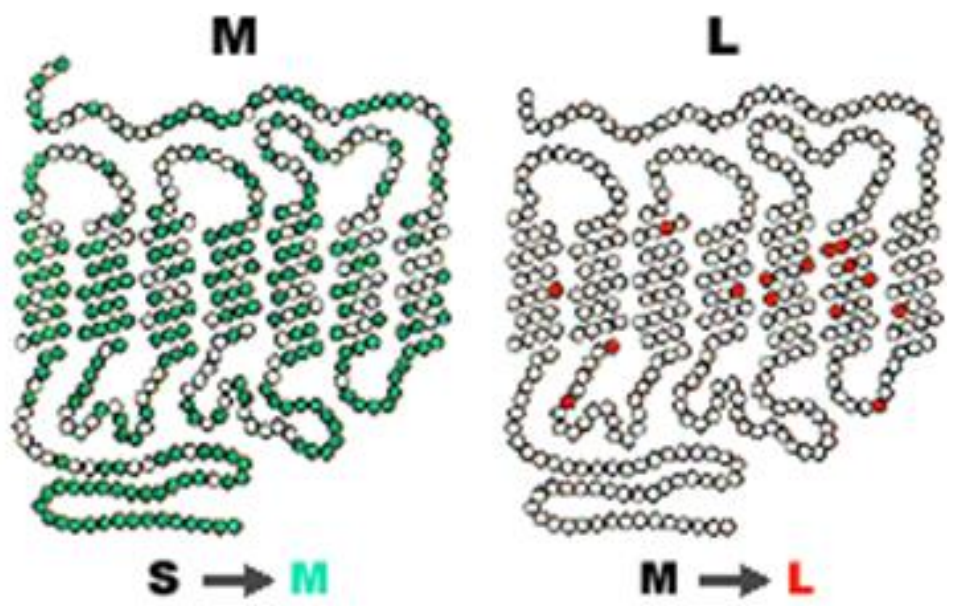

Figura 6. Esquema comparativo da sequência de aminoácidos dos diferentes tipos de pigmentos visuais encontrados em primatas do Novo Mundo e humanos. Os círculos coloridos representam os aminoácidos diferentes da estrutura molecular dos pigmentos e os círculos em branco representam os aminoácidos comuns aos dois pigmentos (http://www.handprint.com/HP/WCL/color1.html\#conechemistry).

Nos mamíferos, a forma mais comum de visão de cores é a dicromacia, que é baseada na presença de dois pigmentos visuais distintos em diferentes cones. Os primatas são os únicos mamíferos conhecidos que possuem uma visão de cor tricromata, ou seja, baseada em três pigmentos visuais com diferentes picos de absorção. As opsinas expressas na retina dos primatas apresentam picos de absorção espectral no violeta ( 420 nm), no vermelho ( 560 nm), e no verde ( 530 nm) (Jacobs, 1998).

Os pigmentos visuais são responsáveis pelo início do processo de transdução do sinal luminoso em sinal neural, a fototransdução (Kawamura, 1993). Com a absorção de um fóton de luz pelo retinal, sua conformação 11-cis-retinal, transforma-se em todotrans-retinal, modificando a conformação da opsina. Após essa transformação, ocorre uma cascata de reações bioquímicas, envolvendo a sinalização mediada pela proteína G, que resulta na alteração do potencial de membrana da célula fotorreceptora em resposta à luz (McBee, Palczewski, Baehr \& Pepperberg, 2001). 
Os sinais dos fotorreceptores são enviados para os neurônios de segunda ordem da camada nuclear interna através das sinapses que ocorrem na camada plexiforme externa (CPE). Na CPE, os fotorreceptores estabelecem contato com células horizontais e bipolares (Cajal, 1893; Dowling e Boycott, 1966). Na camada plexiforme interna encontram-se os terminais axonais das células bipolares, os dendritos de células amácrinas e ganglionares. Os axônios das células ganglionares formam uma camada de fibras nervo ópticas que se dirigem à saída da retina. Essas fibras então unidas formam o nervo óptico que se projeta para as áreas visuais centrais (Figura 7) (Lam, Sefton \& Bennett, 1982).

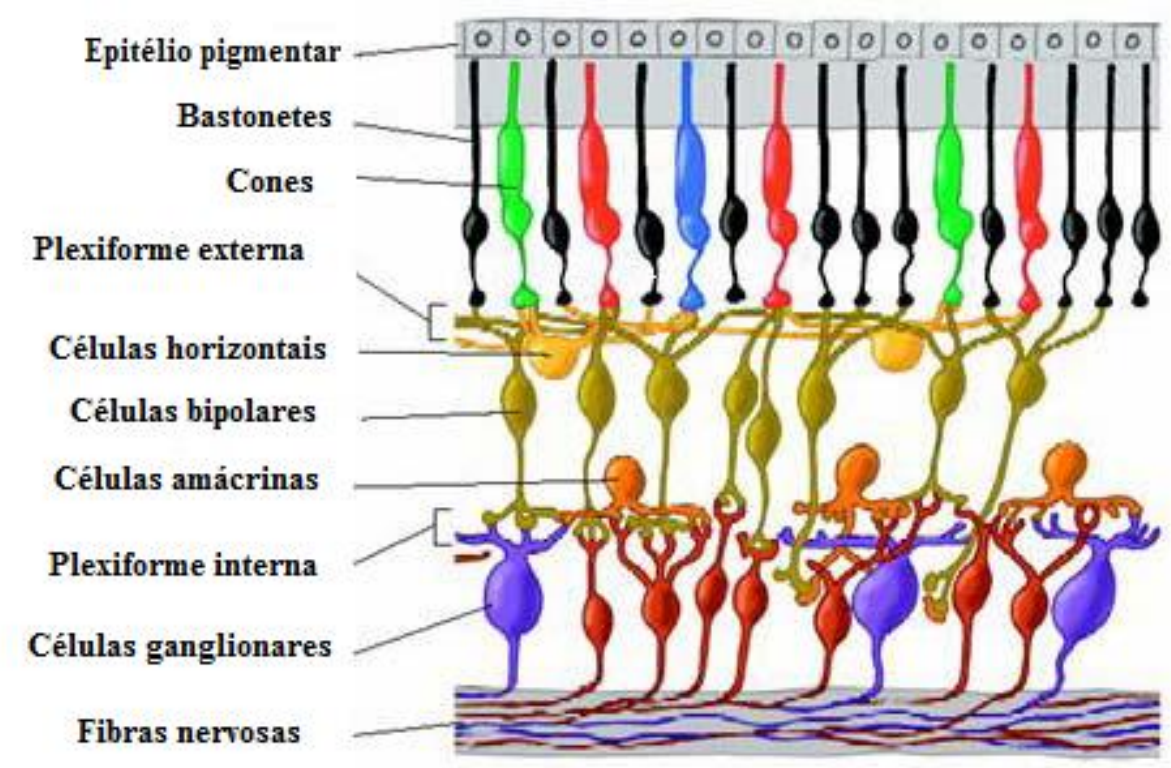

Figura 7. Esquema da organização celular da retina. Modificado de Kolb, 2003.

\subsection{O Processamento da cor}

A visão de cores em vertebrados necessita da presença de pelo menos duas classes de cones, contendo opsinas com sensibilidade espectral distinta, assim como 
mecanismos neurais para que ocorra a comparação dos sinais provenientes da ativação dos diferentes tipos de cones (Cornsweet, 1970; Gegenfurtner \& Kiper, 2003) Este sistema pós-receptoral de comparação dos sinais provenientes dos cones é baseado em canais de oponência cromáticos (De Valois, 1965).

Na retina de alguns vertebrados, como peixes e tartarugas, a oponência cromática é encontrada nas células horizontais (Ventura, Zana, Souza \& De Voe, 2001; Rocha et al., 2008; Joselevitch, John \& Ventura, 2010). Na retina de primatas a oponência cromática ocorre na camada de células ganglionares e seus campos receptivos se organizam de forma concêntrica, com centro e periferia caracterizados por respostas de sinal inverso excitatório ou inibitório (DeValois, 1965; Dacey \& Barry Lee, 1994; Dacey, 1999; Lee, 2004; Silveira et al., 2004).

Uma célula ganglionar com centro tipo vermelho ON (excitado pelo vermelho) e periferia tipo verde OFF (inibido pelo verde) está representada na Figura 8. A frequência de resposta da célula aumenta quando o estímulo ocorre no centro do campo. Quando a área do estimulo excede o tamanho da área central a frequência da resposta diminui. Quando a região periférica é estimulada por uma luz de cor oposta, nesse caso o verde, a resposta é oposta à dada na região central e a taxa de disparos da célula diminui ilustrando a inibição causada pela estimulação da luz verde na periferia do campo receptivo desta célula (Ghosh, Martin \& Grünert, 1997; Calkins, Tsukamoto \& Sterling, 1998). 




(a) Potencisis
registredos




(c)



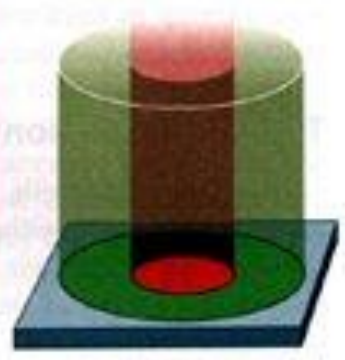

(d)

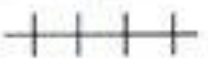

Figura 8. Representação de um campo receptivo de célula ganglionar com oponência cromática. Modificado de Bear, Connors e Paradiso, 2002.

Em primatas existem três classes de células ganglionares especializadas: a do tipo anã, parasol e bi-estratificada. Os axônios das células ganglionares do tipo P ou anã recebem sinais dos cones $\mathrm{M}$ e $\mathrm{L}$ e dirigem-se às camadas parvocelulares do NGL através da via parvocelular de processamento (via P) que possui alta seletividade a estímulos cromáticos vermelho/verde e pouca seletividade a estímulos em movimento e baixo contraste de luminância. As fibras das células ganglionares do tipo $\mathrm{M}$ ou parasol também recebem sinais gerados pelos cones $\mathrm{M}$ e $\mathrm{L}$, esses sinais partem da retina para $\mathrm{o}$ NGL através da via magnocelular de processamento (M) que constitui a base para a formação do canal de luminância e sua função esta relacionada com a detecção e localização dos objetos. As fibras das células ganglionares do tipo bi-estratificada recebem sinais dos cones $\mathrm{S}, \mathrm{M}$ e L e suas projeções são direcionadas ao NGL através da via de processamento koniocelular $(\mathrm{K})$ que está relacionada com o processamento das informações cromáticas do canal de oponência azul/amarelo. Essas vias em conjunto, são fundamentais para a discriminação de cores (Livingstone e Hubel, 1987; Hendry \& Reid, 2000; Surridge et al., 2003; Lee, 2004).

As informações codificadas seguem trajetórias distintas em direção ao sistema nervoso central, formando vias paralelas de processamento neural. Grande parte dos 
axônios de células ganglionares dirige-se ao Núcleo Geniculado Lateral (NGL) que enviam as informações para o córtex visual primário, onde a percepção visual será gerada (Lee, 2004; Iwai \& Kawasaki, 2009).

\subsection{Genética e evolução da visão de cores}

Durante o processo evolutivo, a visão de cores foi selecionada de diferentes formas entre os diferentes grupos de animais. Os mamíferos ancestrais durante a era Paleozóica perderam dois genes que expressam os pigmentos visuais responsáveis pela percepção de estímulos luminosos de comprimento de onda curto (SWS1 ou SWS2) e médio (Rh2) e mantiveram apenas dois genes que expressam os pigmentos visuais, LWS e SWS1 ou SWS2. A classe SWS1 é encontrada em marsupiais e eutérios, e a classe SWS2 em monotremados (Figura 9) (Trezise \& Collin, 2005). 


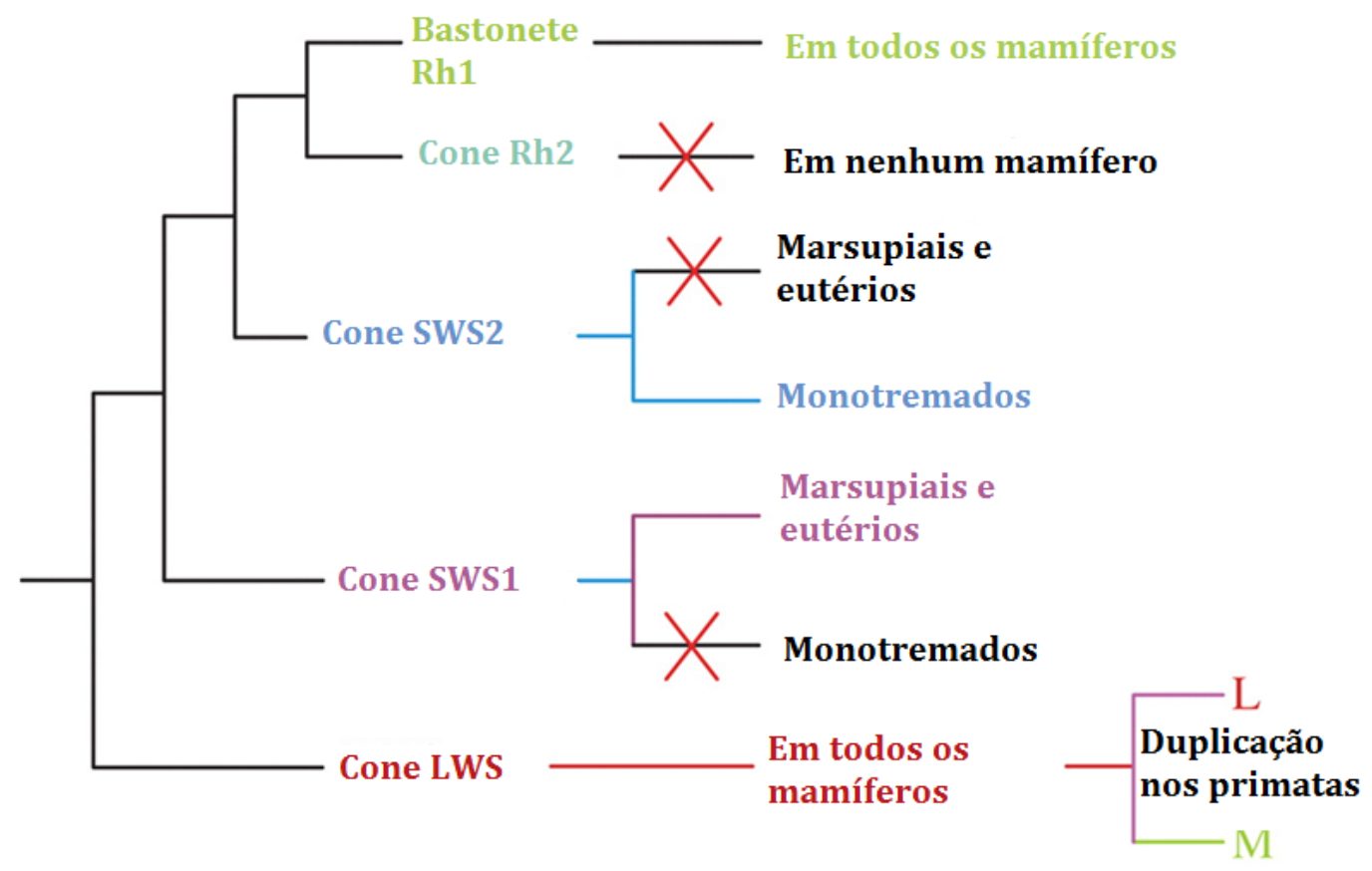

Figura 9. Classes de bastonetes e cones mantidas e perdidas em mamíferos. A origem do L e M variantes do gene de LWS por duplicação de genes em primatas do Velho Mundo, Hominoidea e em primatas do Novo Mundo é mostrado. Modificado de Hunt, Carvalho, Cowing \& Davies (2009).

Os genes expressos nos cones de vertebrados são classificados em 4 grupos de acordo com suas linhagens evolutivas e propriedades espectrais (Figura 10): o grupo sensível ao comprimento de onda curto-1 (SWS1), sensível ao comprimento de onda curto-2 (SWS2), sensível ao comprimento de onda médio ( $\mathrm{Rh2}$ ) e o sensível ao comprimento de onda longo (LWS). O grupo Rh1 é geralmente expresso em bastonetes. (Hunt \& Peichl, 2014). 


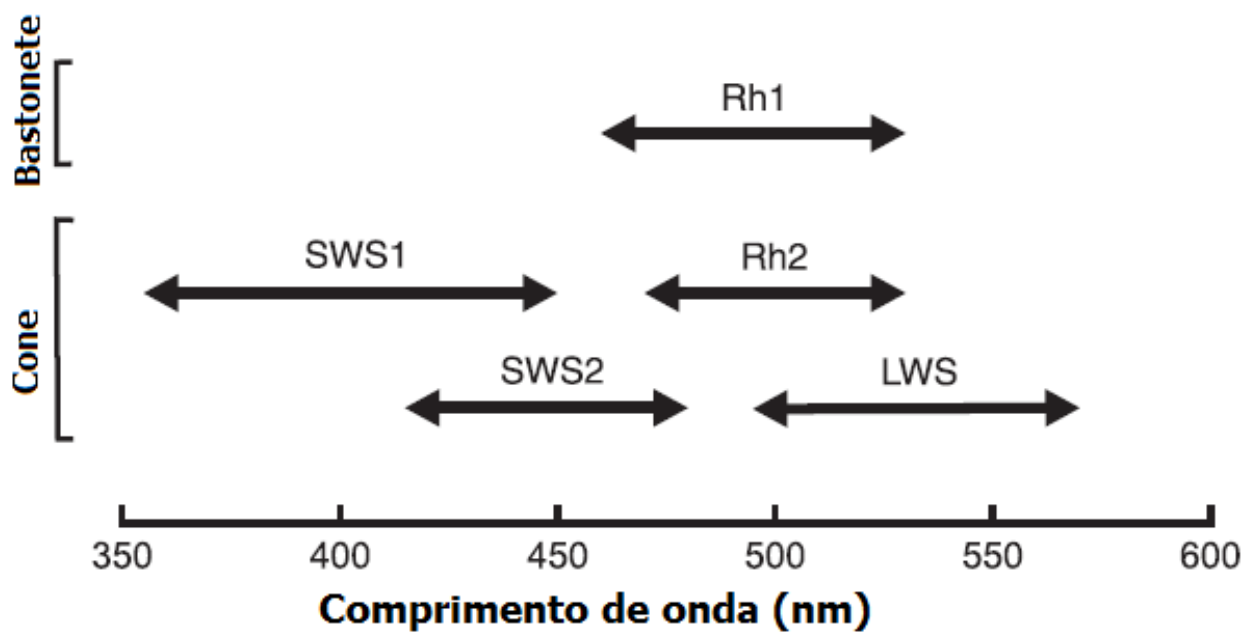

Figura 10. Cinco grupos de genes que expressam os pigmentos visuais encontrados na retina de vertebrados. O gene Rh1 está associado a pigmentos encontrados em bastonetes e os outros quatro genes a pigmentos encontrados em cones. A extensão das linhas horizontais indica a faixa de localização dos picos espectrais dos pigmentos expressos por cada grupo. Modificado de Jacobs (2008).

Em 1939, Grether foi o pioneiro nas pesquisas de visão cores em primatas do Novo Mundo, em um estudo que utilizou testes discriminativos de cores em laboratório usando Cebus e Ateles, foi confirmado que alguns indivíduos apresentaram a percepção de cores assim como ocorre nos daltônicos e uma fêmea respondeu ao teste de forma semelhante a um humano com visão de cores normal, ou seja, tricomata (Grether, 1939 apud Jacobs, 2007). Atualmente sabe-se que essas diferenças são o resultado de mutações que ocorreram provavelmente após a segregação dos primatas do Novo e do Velho Mundo, há cerca de 40 milhões de anos. Eventos de duplicação e mutação dos genes das opsinas aconteceram de forma distinta entre os dois grupos, resultando no surgimento de polimorfismos genéticos responsáveis pelos diferentes fenótipos de visão de cores (Hunt et al., 1998).

Os demais primatas do Novo Mundo apresentam um polimorfismo no gene LWS e são os únicos animais a possuir indivíduos com visão de cor dicromata ou 
tricromata em uma mesma espécie. Os indivíduos do sexo masculino apresentam apenas um alelo no único cromossomo X o qual irá expressar o pigmento LWS ou MWS. Este combinado ao pigmento visual SWS1 resultará em uma visão de cor dicromata. As fêmeas homozigotas, ou seja, que possuem o mesmo gene em ambos os cromossomos sexuais, também apresentam fenótipo dicromata pois expressam apenas dois tipos de genes, o L/MWS e o SWS1. Fêmeas heterozigotas apresentam alelos diferentes nos cromossomos sexuais. A expressão de dois alelos presentes nos cromossomos $\mathrm{X}$ e a expressão do gene SWS1, em três diferentes tipos de cones possibilita uma visão de cores tricromata nestas fêmeas (Jacobs, 1996; Jacobs, 1998; Jacobs \& Deegan II, 1999). Esse tipo de visão de cores ficou conhecido como visão de cores polimórfica e é comum em primatas do Novo Mundo.

Nos primatas a visão de cores tricromata em ambos os sexos ocorre rotineiramente apenas em hominídeos e primatas do Velho Mundo. Nesses grupos o gene LWS presente no cromossomo X sofreu uma duplicação e mutação, originando o gene MWS e, como resultado, estes genes podem codificar diferentes pigmentos nos cones L ou M. Em primatas do Novo Mundo, as espécies do gênero Aotus, apresentam visão monocromata, ou seja, não possuem visão de cores pois expressam apenas um gene nos cones e o gênero Alouatta, é o único gênero dentre os primatas do Novo Mundo a possuírem visão de cor tricromata uniforme em indivíduos de ambos os sexos (Jacobs, 1996; Surridge, Osorio \& Mundy, 2003).

Ainda não se sabe o porquê da tricromacia em Allouatta ter sido selecionada após a divergência dos primatas. Vale ressaltar que a aquisição da tricromacia uniforme nesses animais foi um evento independente da duplicação de genes que deu origem a tricromacia nos primatas do Velho Mundo e hominídeos. 
O gene polimórfico no cromossomo sexual X possui três (ou mais) alelos que codificam opsinas $\mathrm{M} / \mathrm{L}$, juntamente com um lócus presente no cromossomo autossômico, responsável por codificar a opsina expressa pelo gene SWS1 (Jacobs, Deegan, Neitz, Crognale \& Neitz, 1993).

Pigmentos expressos pelo gene SWS1 são classificados como sensíveis ao violeta (VS) ou ao ultravioleta (UV) de acordo com seus picos de sensibilidade espectrais, sendo que o UV é ancestral e tem se mantido em muitas espécies de mamíferos, nos quais incluem alguns roedores, morcegos e marsupiais (Calderone \& Jacobs, 1999).

O desvio espectral para o UV é, em grande parte alcançado por uma única substituição de aminoácido na posição 86 (Hunt et al., 2007). Com a presença do aminoácido fenilalanina nesta posição, os pigmentos absorvem maximamente comprimentos de onda na faixa do UV e quando substituídos pelo aminoácido tirosina como encontrado em marsupiais, bovinos e suínos apresentam pigmentos que absorvem maximamente na região do VS. Nesse caso os deslocamentos podem mudar em até 60 nm o pico de absorção da opsina (Cowing et al., 2002).

As variações encontradas nos diferentes pigmentos expressos pelo gene SWS1, dentro das classes UV e VS, parecem ser determinadas por mutações em diferentes sítios (Yokoyama, 2002). Segundo Shi \& Yokoyama, 2003 existem nove sítios que foram críticos para determinação do comprimento de onda maximamente absorvido pelo pigmento SWS1 durante a evolução dos vertebrados: 46, 49, 52, 86, 90, 93, 114, 116, e 118.

Atualmente existem poucos estudos comparativos sobre a diversidade dos genes que expressam as opsinas, principalmente o gene SWS1, no grupo dos primatas. Das quatro famílias de primatas do Novo Mundo, 11 gêneros foram estudados em relação ao 
pico de absorção espectral das opsinas presentes nos cones L e M. As metodologias utilizadas foram eletrorretinografia, microespectrofotometria, inferência através de análise genética, e medidas in vitro dos pigmentos expressos pelos cones. Esses trabalhos estão resumidos na Tabela 1.

Tabela 1. Resumo dos trabalhos publicados que descrevem o pico de sensibilidade espectral das opsinas em algumas espécies de primatas do Novo Mundo. Modificado de Bonci et al., 2013.

\begin{tabular}{|c|c|c|c|c|c|c|c|c|}
\hline \multirow{3}{*}{$\begin{array}{c}\text { Família } \\
\text { Atelidae }\end{array}$} & \multirow{3}{*}{$\begin{array}{c}\text { Gênero } \\
\text { Ateles }\end{array}$} & \multirow{3}{*}{$\begin{array}{c}\boldsymbol{\lambda} \mathbf{m a x} \\
\mathbf{S} \\
432\end{array}$} & \multicolumn{5}{|c|}{$\lambda \max \mathrm{L} / \mathrm{M}$} & \multirow[t]{2}{*}{ Referências* } \\
\hline & & & & & & 550 & 561 & \\
\hline & & & & & 547 & & 562 & Hiramatsu et al., 2005; (E). \\
\hline & & & & & & 553 & & Hiramatsu et al., 2008; (E). \\
\hline & Brachyteles & & 530 & & & 550 & 562 & Talebi et al., 2006; (I). \\
\hline & Lagothrix & 437 & & & 547 & & 562 & Jacobs \& Deegan II, 2001; (ERG). \\
\hline & & & 530 & & & & 562 & Jacobs et al., 1996; (ERG, I). \\
\hline & Alouatta & & 529 & & & 557 & & Saito et al., 2004; (SUER, MSP). \\
\hline & Hevaria & & 532 & & & & 564 & Matsushita et al., 2014 (ERG) \\
\hline & & & 530 & & & & 562 & Yokoyama et al., 2008 (ERG) \\
\hline \multirow[t]{4}{*}{ Pitheciidae } & Pithecia & & & 537 & & & $\begin{array}{l}563- \\
565\end{array}$ & Jacobs \& Deegan II, 2000/2003; (ERG). \\
\hline & & & & 535 & & 550 & 562 & Boissinot et al., 1998; (I). \\
\hline & Callicebus & & 530 & 535 & 542 & 550 & 562 & Jacobs \& Deegan, 2005; (ERG). \\
\hline & & & & 535 & & 550 & 562 & Bunce et al., 2011; (I). \\
\hline \multirow[t]{16}{*}{ Cebidae } & & $525-527$ & & 534 & & & & Bowmaker et al., 1983; (MPS). \\
\hline & & & & 536 & 549 & & 561 & Jacobs \& Neitz, 1987b; (ERG). \\
\hline & & & 530 & & 545 & & & Saito et al., 2005; (E). \\
\hline & Cebus & & 532 & & 545 & 550 & 560 & Soares et al., 2010; (ERG, I). \\
\hline & & & & 535 & & & 563 & Lee et al., 1996; (SUER, I). \\
\hline & & & & 535 & & 550 & 563 & Lee et al., 2000; (SUER, MSP). \\
\hline & & & & 535 & & & 563 & Saito et al., 2001; (SUER). \\
\hline & & & & & 543 & & & Hiramatsu et al., 2005; (E). \\
\hline & & $425-427$ & & & & & & Jacobs \& Deegan, 2002 \\
\hline & & 430 & & 537 & & 550 & 565 & $\begin{array}{l}\text { Bowmaker et al., 1987/ Mollon et al., 1984; } \\
\text { (MSP). }\end{array}$ \\
\hline & Saimiri & & 532 & & 545 & 558 & & Hiramatsu et al., 2004; (E). \\
\hline & & & & 536 & 548 & & 561 & Jacobs \& Deegan II, 2003 (ERG). \\
\hline & & & & 538 & & 551 & 561 & Jacobs \& Neitz, 1987; (ERG). \\
\hline & Saguinus & & & & 545 & 557 & 563 & Jacobs \& Deegan II, 2003 (ERG). \\
\hline & Leontopithecus & & & & 545 & 557 & & Jacobs \& Deegan II, 2003 (ERG). \\
\hline & Callimico & & & & 543 & & 563 & Surridge \& Mundy, 2002; (I). \\
\hline
\end{tabular}




\begin{tabular}{|c|c|c|c|c|c|}
\hline & 423 & 543 & 556 & 563 & Travis et al.,1988; (MSP). \\
\hline \multirow[t]{5}{*}{ Callithrix } & 539 & & 553 & 561 & Hiramatsu et al., 2004; (E). \\
\hline & & 543 & & 563 & Yeh et al., 1995; (ERG). \\
\hline & 539 & & 553 & 561 & Kawamura et al., 2001 (E) \\
\hline & & 545 & 559 & 567 & Travis et al., 1988 (MPS) \\
\hline & & 543 & 556 & 563 & Tovée et al., 1992 (MPS) \\
\hline Cebuella & & & 556 & 563 & Surridge \& Mundy, 2002; (I). \\
\hline Aotinae & & 543 & & & $\begin{array}{c}\text { Jacobs et al., 1993; (ERG, I, P) } \\
\text { Saito et al., 2001; (SUER). }\end{array}$ \\
\hline
\end{tabular}

*ERG = eletrorretinografia; MSP = microespectrofotometria; $\mathrm{E}=$ medidas in vitro da expressão dos cones; I = inferência a partir de análises genéticas; $\mathrm{P}=$ psicofísica; $\mathrm{SUER}$ = gravação extracelular única unidade.

Muitas espécies nunca tiveram as opsinas presentes nos cones $\mathrm{S}$ estudadas, não havendo informação sobre a variedade alélica do gene $S$ em determinados gêneros de primatas do Novo Mundo. Neste trabalho foram selecionados alguns gêneros de primatas do Novo Mundo que foram pouco estudados, principalmente em relação ao gene SWS1 (Tabela 2).

Tabela 2. Principais aminoácidos responsáveis pela diferenciação do ultravioleta (UV) e do violeta (VS) e absorção espectral da opsina expressa pelo gene SWS1 de diferentes espécies de primatas do Novo Mundo.

\begin{tabular}{|c|c|c|c|c|}
\hline Gênero & Aminoácidos $^{1}$ & Método 2 & $\begin{array}{l}\text { Absorção } \\
\text { espectral }\end{array}$ & Referência \\
\hline Saimiri sciureus & LLPGT & $\mathrm{ME}$ & 430 & Bowmaker et al., 1987 \\
\hline Callithrix Jacchus & LLPGT & ME & 423 & Travis et al., 1988 \\
\hline Cebus apella & LLPAT & ERG & $425-427$ & Jacobs \& Deegan, 2002 \\
\hline Lagothrix lagotricha & LLPAT & ERG & 437 & Jacobs \& Deegan, 2001 \\
\hline Ateles geoffryi & LLPAT & ERG & 432 & Jacobs \& Deegan, 2001 \\
\hline Ateles fusciceps & LLPAT & ERG & 432 & Jacobs \& Deegan, 2001 \\
\hline Ateles belzebuth & - & - & - & - \\
\hline $\begin{array}{l}\text { Brachyteles } \\
\text { arachnoides }\end{array}$ & - & - & - & - \\
\hline Alouatta caraya & - & - & - & - \\
\hline Alouatta clamitans & - & - & - & - \\
\hline
\end{tabular}




\subsection{Ordem Primatas}

A Ordem Primatas pertence a um grupo de mamíferos placentários, no qual estão inseridos os primatas, símios, prossímios, e os seres humanos. Essa ordem é dividida em duas subordens: Strepsirrhini e Haplorrhini (Figura 11). Segundo indícios paleontológicos, a divergência dessas duas subordens pode ter ocorrido entre 63 e 75 milhões de anos atrás (Szaley \& Delson, 1979; Lewis, Jurmain \& Kilgore, 2012).

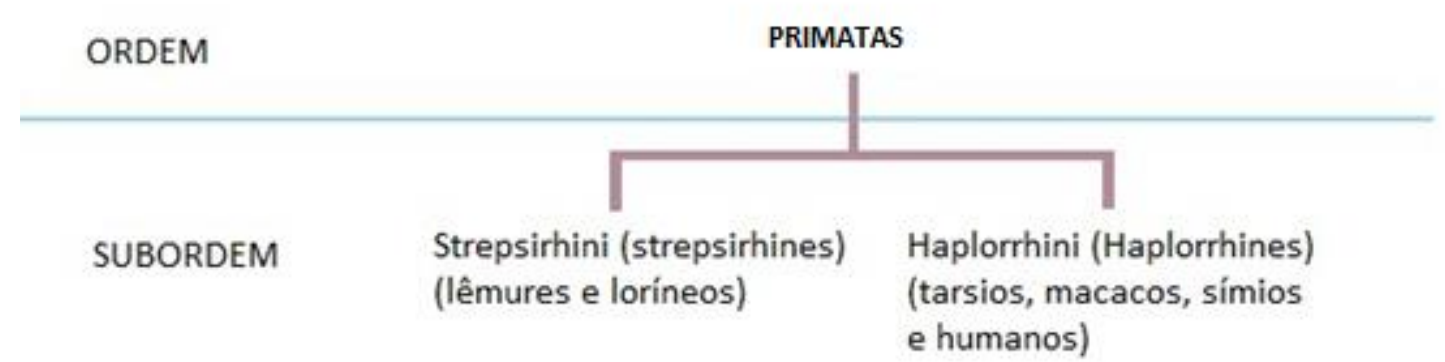

Figura 11. Classificação parcial da ordem Primata, incluindo a divisão das subordens Strepsirhini e Haplorhini. Modificado de Lewis et al. (2012).

Na subordem Strepsirrhini estão inseridos os prossímios, esta é dividida em três infraordens: Lemuriformes, Chiromyiformes e Loriformes e a subordem Haplorrhini é dividida em duas infraordens: Tarsiiformes e Simiiformes, sendo que os Tarsiiformes dividem-se nas famílias Omomyidae e Tarsiidae e nos Simiiformes (antropóides) a divisão ocorre em duas parvordens: Platyrrhini, que incluem os chamados primatas do Novo Mundo, encontrados no continente Americano; e Catarrhini, que incluem os primatas do Velho Mundo, encontrados nos continentes Asiático, Africano e Europeu e os hominóideos. A divergência entre essas duas parvordens aconteceu por volta de 40 milhões de anos atrás (Springer et al., 2012).

$\mathrm{Na}$ parvordem Catarrhini está presente a Superfamília Cercopithecoidea, incluindo os primatas do Velho Mundo e a Superfamília Hominoidea, na qual estão 
presentes os gibões e os gorilas. Na Parvordem Platyrrhini, que inclui primatas do Novo Mundo, está presente a superfamília Cebidae, na qual estão gêneros como Cebus e Callithrix (Goodman et al., 1998). Estas duas parvordens se diferem por uma característica marcante das narinas: em Platyrrhini as narinas são voltadas para os lados, o nariz é achatado e focinho curto, enquanto que nos Catarrhini as narinas são voltadas para baixo e possuem um focinho longo (Groves, 2001; Feagle, 1999).

A forma como o ancestral dos primatas do Novo Mundo chegou à América é incerta. Uma das teorias existentes é de que esses primatas sejam descendentes de prossímios já extintos que viveram na América do Norte. Outra hipótese é de que eles teriam chegado da África por uma travessia, entretanto o modo como fizeram a viagem ainda precisa ser esclarecido. Atualmente sabe-se que várias mudanças climáticas ocorreram nesse período, como por exemplo, variações de temperaturas globais que podem ter afetado o nível do mar, expondo ilhas e criando vias que com ajuda do vento e correntes de águas favoráveis, permitiram a migração da fauna para a América do Sul (Houle 1999; Feagle 1999). Nenhuma das teorias é totalmente aceita devido ao baixo registro fóssil de primatas na América do Sul.

\subsubsection{Primatas do Novo Mundo: Classificação e Características}

A divisão da parvordem Platyrrhini é feita através da diferenciação de algumas características anatômicas e comportamentais, como dentição, conformação da pelagem, unhas, cuidado com a prole, reprodução, capacidade suspensória da cauda entre outras. 
Atualmente, técnicas de cariotipagem e sequenciamento gênico têm sido usados para melhorar os resultados taxonômicos.

A classificação dos primatas do Novo Mundo tem sido um tema de forte debate durante as últimas três décadas. As propostas dos pesquisadores para essa classificação se baseiam principalmente em estudos morfológicos, ecológicos e dados moleculares. Estudos recentes com base em dados da literatura e da citogenética feitos por Groves (2001) propuseram que a Parvordem Platyrrhini divide-se em quatro famílias: Cebidae, Aotidae, Pitheciidae e Atelidae.

Em paralelo com as pesquisas de Groves (2001), Schneider (2000) em suas pesquisas moleculares analisou o DNA de primatas do Novo Mundo a fim de melhorar a classificação desse grupo e os resultados dessas análises agruparam a parvordem Platyrrhini em três famílias: Cebidae, Pitheciidae e Atelidae.

As pesquisas de Schneider (2000) mostraram um forte monofiletismo da família Cebidae, agrupando os gêneros Aotus, Cebus e Saimiri com a Subfamília Callitrichinae e a análise apoiou fortemente a reclassificação de Cebuella como pertencente ao gênero Callithrix e classificou Callimico como um grupo irmão de Callithrix, ao contrário da visão tradicional de que Callimico é um grupo basal de Callithrix.

A análise de Schneider (2000) também mostrou um padrão de ramificação congruente na família Atelidae, colocando Alouatta como a linhagem mais basal e verificou que Brachyteles e Lagothrix compartilham um ancestral comum, contrastando com a visão amplamente divulgada de que Ateles e Brachyteles compartilham o último ancestral comum no clado Atelidae. A Figura 14 mostra a árvore consenso entre os principais protagonistas desta discussão (Schneider, 2000). 
Neste trabalho foram estudados primatas pertencentes aos quatros gêneros da família Atelidae: Brachyteles, Lagothrix, Ateles e Alouatta e dois gêneros da família Cebidae: Callithrix e Cebus.



Figura 12. Árvore filogenética de Primatas do Novo Mundo obtida por máxima parcimônia (MP). Comprimentos dos ramos e desvios-padrão foram estimados com base no método dos mínimos quadrados. Tempos de divergência foram estimados usando a estratégia de relógio molecular local. Valores de MP Bootstrap nos nós foram obtidas em 1000 repetições. Estrelas em nós significam BS (Bootstrapping) de 99$100 \%$. O índice de comprimento e consistência da árvore MP foi 2,855 e 0,83, respectivamente. Modificado de Schneider (2000). 
Os primatas do Novo Mundo compreendem as espécies que vivem nas florestas tropicais das Américas do Sul e Central. São primatas de tamanho pequeno a médio, pesando de 100 g a $13 \mathrm{~kg}$. Arborícolas, possuem uma locomoção predominantemente quadrúpede, com algumas espécies apresentando uma cauda preênsil (Aguirre, 1971; Stevenson \& Rylands, 1988; Feagle, 1999).

Existem aproximadamente 300 espécies de primatas do Novo Mundo e eles apresentam uma variação considerável no tamanho, dieta e adaptação ecológica, sendo encontrados majoritariamente em áreas florestais da América do Sul, sul do México e América Central (Figura 13) (Feagle, 1999; Lewis et al., 2012).

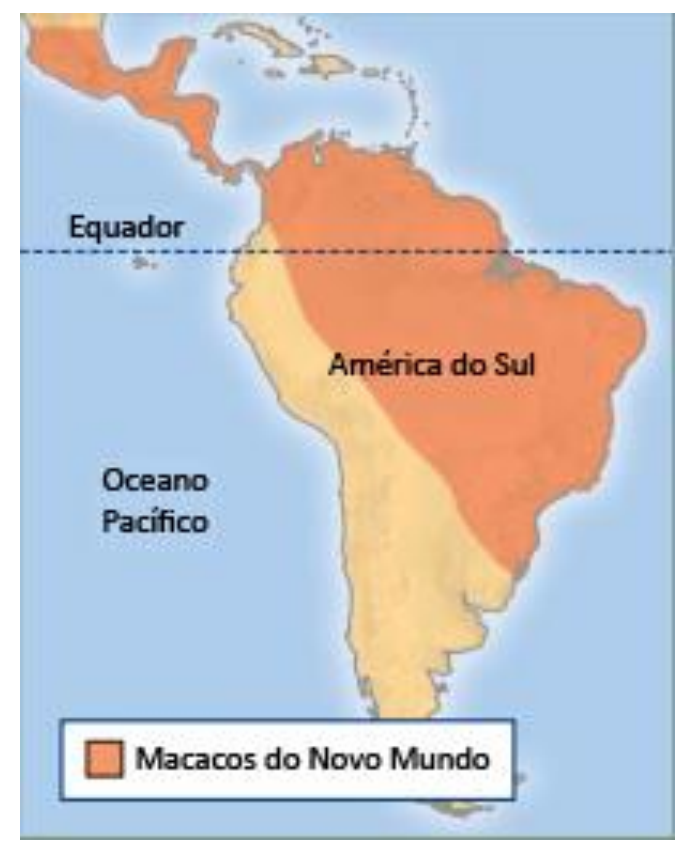

Figura. 13. Distribuição geográfica dos primatas do Novo Mundo atuais. Modificado de Lewis et al. (2012).

Alguns indivíduos, como os pertencentes ao gênero Ateles vivem exclusivamente nas amplas áreas de florestas tropicais das Américas do Sul. Espécies pertencentes ao gênero Lagothrix possuem distribuições geográficas ainda mais 
delimitadas, principalmente por rios na Amazônia (Fooden, 1963; Zanon, Reis \& Ortêncio Filho et al., 2008). Outras espécies possuem ampla distribuição e podem ser encontrados em um vasto território, como é o caso de algumas espécies pertencentes aos gêneros Alouatta, Cebus e Callithrix, que podem ocupar além de florestas, também a caatinga, cerrado, campos e mangues (Stevenson \& Rylands, 1988; Gregorin, 2006; Alfaro et al., 2012). Na Tabela 3 estão resumidas algumas características de alguns gêneros de primatas do Novo Mundo analisados neste trabalho.

Tabela 3. Descrição de características gerais apresentadas nos gêneros de primatas do Novo Mundo analisados neste trabalho.

\begin{tabular}{cccccc}
\hline Gêneros & $\begin{array}{c}\text { Dimorfismo } \\
\text { Sexual } \\
\text { (coloração) }\end{array}$ & Alimetação & Hábito & Particularidade & $\begin{array}{c}\text { Visão de } \\
\text { cores }\end{array}$ \\
\hline Callithrix & Não & $\begin{array}{c}\text { Frutas, insetos, } \\
\text { flores e exsudados }\end{array}$ & Diurno & Quimeirismo & Polimórfica \\
Cebus & Não & Frutas e insetos & Diurno & Utilizam ferramentas & Polimórfica \\
Lagothrix & Não & $\begin{array}{c}\text { Frutas, folhas, } \\
\text { flores, insetos, } \\
\text { anfíbios e répteis }\end{array}$ & Diurno & $\begin{array}{c}\text { Classificado como } \\
\text { vulnerável (VU) na } \\
\text { lista vermelha da } \\
\text { IUCN* }\end{array}$ & Polimórfica \\
Ateles & Não & $\begin{array}{c}\text { Frutas, folhas e } \\
\text { flores }\end{array}$ & $\begin{array}{c}\text { Diurno e } \\
\text { crepuscular }\end{array}$ & $\begin{array}{c}\text { Classificado como } \\
\text { vulnerável (VU) na } \\
\text { lista vermelha da } \\
\text { IUCN* }\end{array}$ & Polimórfica \\
Brachyteles & Não & $\begin{array}{c}\text { Folhas, frutos, } \\
\text { brotos e flores. }\end{array}$ & Diurno & $\begin{array}{c}\text { Constam na Lista } \\
\text { Oficial da Fauna } \\
\text { Brasileira Ameaçada } \\
\text { de Extinção }\end{array}$ & Polimórfica \\
Alouatta & Sim & $\begin{array}{c}\text { Folhas, frutas e } \\
\text { flores }\end{array}$ & $\begin{array}{c}\text { Diurno e } \\
\text { crepuscular }\end{array}$ & $\begin{array}{c}\text { Comunicam-se por } \\
\text { vocalização }\end{array}$ & Tricromacia \\
uniforme
\end{tabular}

* União Internacional para a Conservação da Natureza.

A alimentação desses primatas é basicamente constituída por frutas, podendo ocorrer diferentes tipos complementação na dieta com folhas, flores, insetos, (Defler, 2004), com exceção do gênero Allouata que apresentam uma dieta folívora-frugívora 
(Neville, Glander, Braza \& Rylands 1988). Dependendo das condições ambientais, grande parte dos primatas do Novo Mundo é adaptável às diversas condições ambientais e podem viver com alimentos não usuais em condições normais (Van Roosmalen, 1985; Stevenson \& Rylands, 1988; Kowalewaky \& Zunino, 1999; Defler, 2004; Talebi, Bastos \& Lee, 2005).

Algumas espécies estão ameaçadas de extinção devido à caça, ao desmatamento, ao tráfico e a reprodução vagarosa, com destaque para as espécies Brachyteles hypoxanthus e Brachyteles arachnoides que constam na lista oficial da Fauna Brasileira ameaçada de extinção e Lagothrix e Ateles que atualmente são classificados como vulnerável na lista vermelha da IUCN (União Internacional para a Conservação da Natureza) (Van roosmalen \& Klein, 1988; Jerusalinsky, Talebi \& Mello et al., 2011).

$\mathrm{Na}$ reprodução do gênero Callithrix é comum o nascimento de gêmeos dizigóticos, mesmo os fetos dividindo a placenta e o saco amniótico. A placenta consiste em dois discos placentários faceados e há, portanto, conexões dos vasos sanguíneos entre os gêmeos. Isto resulta no quimerismo de sangue e como resultado cada um dos gêmeos carrega material genético do outro. Isto é muito raro em outros mamíferos, mas frequente em calitriquídeos (Ross, French \& Ort1, 2007).

A grande maioria desses primatas possui hábito diurno, podendo ser encontrado algumas espécies com hábitos crepusculares, os quais apresentam picos de movimentação no meio da manhã e no meio da tarde. Também vale ressaltar a exceção do gênero Aotus, que possuem hábitos noturnos (Stevenson \& Rylands, 1988; Biccamarques \& Calegaro-Marques, 1994; Defler, 2004). 


\subsection{Ecologia Visual}

A visão é o principal sentido dos primatas e os membros dessa ordem possuem considerável variação nas suas capacidades visuais, em relação a visão de cores, o que pode afetar como esses animais veem e interagem com o seu ambiente (BuchananSmith, 2005).

Uma diferença marcante entre os primatas do Novo Mundo e os primatas do Velho Mundo é a visão de cores (Jacobs \& Deegan, 1999). O polimorfismo visual encontrado nos primatas do Novo Mundo torna diferente a variedade de cores que podem ser discriminadas mesmo entre indivíduos da mesma espécie e sexo. Esse polimorfismo pode ter sido a situação ancestral à tricromacia uniforme nos primatas do Velho Mundo (Jacobs, 2007; Jacobs, 2008).

As vantagens e desvantagens da tricromacia nos primatas ainda são pouco discutidas e estudadas. Atualmente existem algumas hipóteses, como a da frugívoria, na que animal obtém vantagens ao discriminar frutos maduros e imaturos em meio à folhagem verde, especialmente a longas distancias e a hipótese da folívoria, na qual o animal tricromata se sobressai ao discriminar folhas jovens e maduras (Surridge et al., 2003; Dominy, Svenning \& Li, 2003; Vorobyev 2004).

Alguns pesquisadores defendem que a tricromacia favoreceria tanto a frugívoria quanto a folívoria, pois ambos os itens alimentares em questão podem ser distinguíveis a partir de um fundo formado por folhas maduras (Sumner \& Mollon, 2000). Em um estudo comportamental feito com Callithrix geoffroyi Caine \& Mundy (2000), observaram que indivíduos tricromatas encontraram significativamente mais objetos laranja do que os indivíduos dicromatas quando este estava entre as folhagens. 
Entretanto a dicromacia também pode ser vantajosa. Pesquisadores demonstraram que a dicromacia pode garantir outras vantagens perceptuais, como a detecção de objetos camuflados, já que esses indivíduos são guiados por fatores como brilho, textura e forma (Saito, 2005). Dicromatas também apresentam uma visão escotópica melhor, quando comparada aos tricromatas, isto representaria uma vantagem seletiva, em condições de luminosidade baixa, o que aumenta consideravelmente a chance de detecção de movimentos de predadores e alimentos camuflados, este importante no forrageamento de insetos e de frutos crípticos (camuflados pela cor e ou iluminação). Esses fatores podem explicar a manutenção deste polimorfismo visão de cores em primatas (Morgan, Adam \& Mollon, 1992; Melin, Fediganet, Hiramatsu \& Kawamura, 2007; Verhulst e Maes, 1998).

Mollon (1989) sugeriu que as fêmeas heterozigotas tricromatas, entre todos os indivíduos do grupo teriam a tarefa de procurar por frutos maduros e apontou a hipótese de que a dicromacia pode ter sido mantida devido à sua vantagem na quebra de camuflagem e de identificação de alimentos crípticos, insetos e ou predadores. Com isso, o polimorfismo visual em indivíduos da mesma espécie pode ter uma vantagem cooperativa e pode ser responsável pela manutenção da dicromacia e tricromacia em primatas do Novo Mundo (Tovée, Bowmaker \& Mollon, 1992; Morgan et al. 1992; Sumner \& Mollon, 2000).

Entretanto, em um estudo recente com Cebus capucinus foi observado que não houve diferença do tempo investido na procura de alimentos entre dicromatas e tricomatas (Melin 2008). Este estudo, corrobora o de Dominy et al., (2003), no qual concluiu que nas espécies Saguinus imperator imperator e Saguinus fuscicollis wedelli não há diferença no sucesso de aquisição de frutos entre os indivíduos quando guiados pela pista de coloração. 
Além da busca de alimentos e da detecção de predadores, ainda existem outros aspectos comportamentais que podem envolver a visão de cores e que ainda precisam ser estudados, como por exemplo, a identificação social de indivíduos quando associado à cor da pelagem, o que pode evitar confrontos com animais dominantes (Caro 2005; Bradley \& Mundy 2008). Benefícios reprodutivos também podem ocorrer, quando há o dimorfismo sexual na espécie e a visão de cores pode favorecer indivíduos capazes de identificar uma fêmea. Em alguns casos é possível detectar mudanças na coloração da pele que ocorre devido à oxigenação sanguínea e que pode sinalizar a época reprodutiva de uma fêmea (Waitt et al. 2003; Bradley \& Mundy 2008).

Pouco se conhece a respeito dos motivos da seleção da visão de cores nos primatas, podendo-se, no máximo, especular seus meios e prováveis fins (Surridge et al., 2003). 


\section{Justificativa}

O estudo genético da visão de cores é essencial para compreensão do processamento e da sensação de cor e pode ajudar a entender a evolução da visão de cores nos primatas tornando-os um modelo valioso para a compreensão da visão humana

O polimorfismo da visão de cores dos primatas do Novo Mundo os torna um valioso modelo de estudo para compreensão da plasticidade do sistema visual a diferentes ambientes. O resultado do processamento sensorial das informações ambientais, como a sensação de cor é fundamental para tomada de decisões comportamentais e podem ter importância na defesa contra predadores, escolha de alimentos, estratégias reprodutivas entre outros (Barros \& Pessoa, 2012).

Outras características tornam algumas espécies de primatas do Novo Mundo do ponto de vista etológico, bons modelos para estudo como: longa expectativa de vida (infância e juventude prolongada), alta taxa de encefalização, grande tendência à exploração e manipulação, partilha de alimentos, dieta onívora, além de comportamentos sociais complexos como cooperação e formação de coalisões (Fragaszy et al., 2004).

Estudos sobre a diversidade de genes que expressam as opsinas em primatas ainda são escassos. O presente trabalho visa preencher as lacunas existentes na literatura a respeito da variabilidade dos genes expressos na retina dos primatas do Novo Mundo. 


\section{Objetivo}

Caracterizar a diversidade dos pigmentos visuais (SWS1) das espécies de primatas do Novo Mundo Cebus apella, Callithrix jacchus, Brachyteles arachnoides, Lagothrix lagothricha, Ateles belzebuth, Alouatta caraya e Alouatta clamitans e dos pigmentos visuais (LWS/MWS) da espécie Callithrix jacchus através de análises genéticas e descrever a sequência de aminoácidos observados para estimar o pico de sensibilidade espectral das opsinas. 


\section{Materiais e métodos}

\subsection{Sujeitos}

O projeto foi aprovado pelo comitê de Ética da UFPA, processo No PS001/2005 e pela UFRN, processo N$^{\circ}$ 045/2009.

Amostras de fezes, sangue e ou pelo foram coletadas de animais do Centro Nacional de Primatas (Cenp) do Instituto Evandro Chagas, localizado na Universidade Federal do Pará (UFPA), da Universidade Federal do Rio de Janeiro (UFRJ), do Parque Ecológico do Tietê, em São Paulo, do Parque Zoológico Municipal Quinzinho de Barros (PZMQB), em Sorocaba e da Universidade Federal do Rio Grande do Norte (UFRN).

As espécies estudadas são pertencentes às famílias Cebidae e Atelidae e estão representados na Tabela 2.

Tabela 4. Espécies de primatas do Novo Mundo estudadas no presente trabalho.

\begin{tabular}{lccccc}
\hline Família & Subfamília & Gênero & Espécie & Nome comum & Origem* \\
\hline \multirow{2}{*}{ Cebidae } & Cebinae & Cebus & apella & Macaco prego & $\begin{array}{c}\text { UFRJ e } \\
\text { UFPA }\end{array}$ \\
\cline { 2 - 5 } & Callitrichinae & Callithrix & jacchus & Sagui-comum & UFRN \\
\hline \multirow{4}{*}{ Atelidae } & Alelinae & Alouata & clamitans & Bugio-ruivo & \\
\cline { 3 - 5 } & & Lagothrix & lagothricha & Macaco-barrigudo & \multirow{2}{*}{ PET e } \\
\cline { 3 - 5 } & & Ateles & belzebuth & Macaco- Aranha & \\
\cline { 3 - 4 } & & Brachyteles & arachnoides & Muriqui-do-sul & \\
\hline
\end{tabular}

*Universidade Federal do Rio de Janeiro (UFRJ); Universidade Federal do Pará (UFPA); Universidade Federal do Rio Grande do Norte (UFRN); Parque Ecológico do Tietê (PET); Parque Zoológico Municipal Quinzinho de Barros (PMZQB).

\subsubsection{Grupo experimental (Gene SWS)}


Foram coletadas fezes, sague e ou pelo de indivíduos da espécie Cebus cf. apella (Sapajus), mantidos na UFRJ $(\mathrm{N}=13)$ e na UFPA $(\mathrm{N}=16)$, Callithrix jacchus $(\mathrm{N}=35)$, mantidos na UFRN e de Brachyteles arachnoides $(\mathrm{N}=6)$, Lagothrix lagotricha $(\mathrm{N}=2)$, Alouatta caraya $(\mathrm{N}=3)$, Alouatta clamitans $(\mathrm{N}=7)$ e Ateles belzebuth $(\mathrm{N}=4)$, mantidos no Parque Ecológico do Tietê, em São Paulo e no Parque Zoológico Municipal Quinzinho de Barros (PMZQB), em Sorocaba-SP.

O éxon 1 do gene SWS1 foi analisado e os aminoácidos das posições 46, 49, 50, 52, 86, 90, 93, 114, 116 e 118 foram identificados. O pico de absorção espectral da opsina foi estimado a partir da sequência de aminoácidos observada nestes sítios específicos.

\subsubsection{Grupo experimental (Gene LWS/MWS)}

Foram coletados fezes e pelos de animais da espécie Callithrix jacchus $(\mathrm{N}=35)$, sendo um grupo mantido em cativeiro e outro de vida livre, ambos do estado do Rio Grande do Norte.

Os éxons 3 e 5 dos genes $\mathrm{M}$ e L foram analisados e os aminoácidos das posições 180 do éxon 3 e 277 e 285 do éxon 5 foram identificados.

\subsection{Análise Genética}

Em laboratório, foi realizada a extração de DNA de amostras de sangue, fezes e ou pelo, utilizando os seguintes kits: PUREGENE® DNA purification Kit (Gentra Systems), QIAamp DNA Stool Mini Kit (Gentra Systems) e QIAamp DNA Investigator Kit (Gentra Systems) de acordo com o protocolo do fabricante. 
Após obtenção do DNA, a reação em cadeia da polimerase (PCR) foi utilizada para amplificar o gene que codifica a opsina $\mathrm{S}$ e as opsinas L/M. Os primers utilizados foram os descritos na tabela 3.

Tabela 5. Descrição dos Primers e temperatura de anelamento destes ao DNA

\begin{tabular}{cccl}
$\begin{array}{c}\text { Sequência } \\
\text { amplificada }\end{array}$ & $\begin{array}{c}\text { Identificação do } \\
\text { primer }\end{array}$ & $\begin{array}{c}\text { Temp. de } \\
\text { anelamento }\left(\mathrm{C}^{\circ}\right)\end{array}$ & Sequência de nucleotídeos do primer \\
\hline $\begin{array}{c}\text { Exon } 3 \text { do gene Le } \\
\mathrm{M}\end{array}$ & $\begin{array}{c}\text { NWMonk5'x3 } \\
\text { NWMonk3'x3 }\end{array}$ & 66 & $\begin{array}{l}\text { CGTCTGTCTGCTCTCCCCTA } \\
\text { TTGCCTCAGGGTCACAGAGT }\end{array}$ \\
\hline $\begin{array}{c}\text { Exon 5 do gene Le } \\
\mathrm{M}\end{array}$ & $\begin{array}{c}\text { CebusMonk5'x5 } \\
\text { CebusMonk3'x5 }\end{array}$ & 66 & $\begin{array}{l}\text { GTGGCAAAGCAGCAGCAGAAAG } \\
\text { CTGCCGGTTCATAAAGACATAG }\end{array}$ \\
\hline $\begin{array}{c}\text { Exon 3 do gene Le } \\
\mathrm{M}\end{array}$ & $\begin{array}{c}\text { Callit_Ex3_FW } \\
\text { Callit_Ex3_RV }\end{array}$ & 60 & $\begin{array}{l}\text { GGATCACGGGTCTCTGGT } \\
\text { CTGCTCCAACCAAAGATG }\end{array}$ \\
\hline Exon 1 do gene S & $\begin{array}{c}\text { BlueExon1FW } \\
\text { BlueExon1RV }\end{array}$ & 60 & $\begin{array}{l}\text { AAGAGGACTCAGAGGAGGGTGTG } \\
\text { CTAACCCCTTTTTCCCCTGC }\end{array}$ \\
\hline
\end{tabular}

Os kits utilizados para PCR foram Platinum ${ }^{\circledR}$ Taq DNA Polymerase (LifeTechnologies Carlsbad, California, USA) e o rTth DNA Polymerase (LifeTechnologies). Em tubos de $1.5 \mathrm{ml}$ foram adicionados $1.5 / 2.5 \mathrm{ml} \mathrm{de} \mathrm{MgCl} 2$ (20 $\mathrm{mM}$ ), 1/2 ml de deoxi-nucletídeos trifosfatos (dATP, dCTP, dGTP, dTTP), 2.5/5 ml de tampão (10x buffer), $0.5 / 1 \mathrm{ml}$ de cada primer, $37 / 40 \mathrm{ml}$ de água deionizada e $0.2 / 0.5 \mathrm{ml}$ de enzima. As reações de PCR foram feitas no termociclador Veriti ${ }^{\mathrm{TM}}$ Dx Thermal Cycler (LifeTechnologies) e seus parâmetros foram ajustados conforme os primers e as amostras.

Após a reação de PCR foi realizada a eletroforese do produto da reação em gel de agarose a $1 \%$. Os produtos de PCR foram purificados com o Kit PureLink® PCR Purification Kit (LifeTechnologies) de acordo com o fabricante.

Os sequenciamentos foram realizados com o kit BigDye ${ }^{\circledR}$ Terminator v3.1 Cycle Sequencing kit (LifeTechnologies) utilizando o sequenciador 3500 Applied Biosystems 
(LifeTechnologies), do Laboratório do Instituto Israelita de Ensino e Pesquisa do Hospital Albert Einstein (IIEPAE).

Após o sequenciamento os resultados foram analisados com o programa BioEdit (v7.0.9) e posteriormente comparados com sequências já descritas na literatura. A estimativa do pico de absorção espectral a partir dos alelos encontrados em cada espécie foi feita conforme Asenjo et al. (1994).

\subsection{Determinação da curva de absorção espectral das opsinas}

Os aminoácidos das posições 50, 52, 86, 93, 114 e 118 expressos pelo éxon 1 do gene SWS1, da posição 180 expresso pelo éxon 3 e das posições 277 e 285 expressos pelo éxon 5, foram considerados na inferência do pico de absorbância espectral das opsinas dos primatas (Asenjo et al., 1994; Shi \& Yokoyama, 2003). Os gráficos com as curvas de absorção espectral foram elaborados pelo Dr. Balázs Vince Nagy com base no trabalho de Stockman \& Sharpe (2000). 


\section{Resultados}

\subsection{Gene SWS1}

$\mathrm{Na}$ análise dos sequenciamentos do gene SWS1 para as espécies Callithrix jacchus, Cebus apella, Brachyteles arachnoides, Lagothrix lagotricha, Alouatta caraya, Alouatta clamitans e Ateles belzebuth não se observou variação alélica entre indivíduos do mesmo gênero. As diferenças encontradas em relação a indivíduos de diferentes espécies estão descritos na Tabela 6.

Tabela 6. Descrição dos aminoácidos encontrados em diferentes sítios do gene SWS1, nas diferentes espécies de primatas do Novo Mundo e o pico de absorção espectral inferido a partir das sequências de aminoácidos.

\begin{tabular}{|c|c|c|c|c|c|c|c|c|c|c|c|}
\hline \multirow{2}{*}{ Espécies } & \multicolumn{10}{|c|}{ Aminoácidos } & \multirow{2}{*}{$\begin{array}{c}\text { Absorção } \\
\text { espectral } \\
(I)^{*}\end{array}$} \\
\hline & 46 & 49 & 50 & 52 & 86 & 90 & 93 & 114 & 116 & 118 & \\
\hline Callithrix jacchus & I & $\mathrm{L}$ & I & $\mathrm{L}$ & $\mathrm{L}$ & $\mathrm{S}$ & $\mathrm{P}$ & $\mathrm{G}$ & $\mathrm{L}$ & $\mathrm{T}$ & 423 \\
\hline Cebus cf. apella & I & $\mathrm{L}$ & $\mathrm{V}$ & $\mathrm{L}$ & $\mathrm{L}$ & $\mathrm{S}$ & $\mathrm{P}$ & A & $\mathrm{L}$ & $\mathrm{T}$ & $425-427$ \\
\hline $\begin{array}{l}\text { A. caraya e } A . \\
\text { clamitans }\end{array}$ & I & $\mathrm{L}$ & A & $\mathrm{L}$ & $\mathrm{L}$ & $\mathrm{S}$ & $\mathrm{P}$ & $\mathrm{G}$ & $\mathrm{L}$ & $\mathrm{T}$ & 430 \\
\hline $\begin{array}{l}\text { Brachyteles } \\
\text { arachnoides }\end{array}$ & I & $\mathrm{L}$ & A & $\mathrm{L}$ & $\mathrm{L}$ & $\mathrm{S}$ & $\mathrm{P}$ & A & $\mathrm{L}$ & $\mathrm{T}$ & $432-437$ \\
\hline $\begin{array}{l}\text { Lagothrix } \\
\text { lagotricha }\end{array}$ & I & $\mathrm{L}$ & A & $\mathrm{L}$ & $\mathrm{L}$ & $\mathrm{S}$ & $\mathrm{P}$ & A & $\mathrm{L}$ & $\mathrm{T}$ & $432-437$ \\
\hline Ateles belzebuth & I & $\mathrm{L}$ & A & $\mathrm{L}$ & $\mathrm{L}$ & $\mathrm{S}$ & $\mathrm{P}$ & A & $\mathrm{L}$ & $\mathrm{T}$ & $432-437$ \\
\hline
\end{tabular}

* $(\mathrm{I})=\mathrm{I}$ = inferência a partir de análises genéticas. Em negrito, aminoácidos mais importantes para o deslocamento espectral da opsina SWS1.

Ao analisar nove sítios críticos para determinação do comprimento de onda do pigmento SWS1 durante a evolução dos vertebrados $(46,49,52,86,90,93,114,116$, e 118), juntamente com o sítio 50, observou-se algumas diferenças entre as espécies de primatas do Novo Mundo analisados (Shi \& Yokoyama, 2003). As sequências de 
aminoácidos encontradas nessas posições (46, 49, 50, 52, 86, 90, 93, 114, 116 e 118), respectivamente, foram ILILLSPGLT para C. jacchus, ILVLLSPALT nos indivíduos da espécie C. apella, ILALLSPALT nas espécies L. lagotricha, A. belzebuth e $B$. arachnoides, e ILALLSPGLT em A. caraya e A. clamitans.

A origem do pigmento violeta e a subsequente restauração dos pigmentos UV em algumas espécies são causadas por substituições de aminoácidos nas posições 52 , 86, 93, 114 e 118 (Shi \& Yokoyama, 2003). Ao analisar essas posições, foram encontradas duas combinações de sequências dos aminoácidos devido à variação Glicina (G) e Alanina (A) na posição 114. Entre os seis gêneros estudados, Callithrix e Alouatta apresentaram a sequência LLPGT e os demais apresentaram a sequência LLPAT. Na posição 50, também foram observadas diferenças entre as espécies. Nessa posição em Callithrix está presente o aminoácido isoleucina (I), em Cebus o aminoácido Valina (V) e nos demais gêneros o aminoácido Alanina (A).

O pico de sensibilidade espectral foi estimado para todas as espécies por inferência, a partir das análises genéticas e dados da literatura. Em Callithrix o pico foi estimado em $423 \mathrm{~nm}$, devido a este ter apresentado a sequência LLPGT e I na posição 50. Os indivíduos das duas espécies do gênero Alouatta apresentaram a sequência LLPGT com A na posição 50, com isso o pico foi estimado em 423-430 nm. Em Cebus o pico foi estimado em 425 - $427 \mathrm{~nm}$ com base na sequência LLPAT e por apresentar V na posição 50. Os demais (Brachyteles, Lagothrix e Ateles) apresentaram a sequência de aminoácidos LLPAT e A na posição 50, com isso o pico de absorção espectral desses indivíduos foi estimado entre 432 - 437 nm (Travis et al., 1988; Jacobs \& Deegan, 2001, 2002). 


\subsection{Gene LWS e MWS}

Nos resultados do sequenciamento do gene LWS/MWS de Callithrix jacchus foi observada a presença de 5 alelos diferentes (SFT, SYT, SYA, AYA e AYT). A estimativa do pico de absorção espectral dos indivíduos foi feita conforme Asenjo et al (1994), com exceção da sequência de aminoácidos SYA, na qual não foi possível fazer a estimativa devido a essa sequência ainda não ter sido descrita na literatura (Tabela 9) Os dados completos do sequenciamento encontra-se no Anexo 1.

Indivíduos com apenas um alelo foram classificados em dicromatas e indivíduos com dois alelos como tricromatas. Alguns genótipos não puderam ser determinados devido ao alelo não poder ser determinado nesses indivíduos. 
Tabela 7. Posições dos aminoácidos encontrados em indivíduos da espécie Callithrix jacchus.

\section{Callithrix jacchus}

\begin{tabular}{cccccc}
\hline Sexo (N) & Alelo1 & Alelo 2 & $\max$ K1 & $\max$ K2 & Fenótipo \\
\hline M (12) & SYT & & $560-563$ & dicromata \\
\hline M (5) & SYT & SFT & $560-563$ & $546-553$ & tricromata \\
\hline M (1) & SFT & & $546-553$ & dicromata \\
\hline F (7) & SYT & & $560-563$ & dicromata \\
\hline F (3) & SYT & SFT & $560-563$ & $546-553$ & tricromata \\
\hline F (2) & ND & ND & ND & ND & ND \\
\hline F (2) & SYT & SYA & $560-563$ & ND & ND \\
\hline F (1) & AYT & & $550-556$ & dicromata \\
\hline & & & & & \\
\hline
\end{tabular}

$\mathrm{M}=$ macho; $\mathrm{F}=$ fêmea; $\mathrm{N}=$ número de indivíduos que apresentaram o mesmo resultado; $\mathrm{S}=$ serina $; \mathrm{Y}=$ tirosina $; \mathrm{T}=$ treonina; $\mathrm{A}=$ alanina $\mathrm{F}=$ fenilalanina $; \lambda \max =$ sensibilidade espectral máxima. ND = não determinado. 


\section{Discussão}

\subsection{Gene SWS1}

Estudos de microespectrofotometria do pigmento SWS1 de humano mostrou que o pico de absorção espectral ocorre em 414 nm (Fasick et al., 1999). Nas espécies de primatas, que tiveram seus genes SWS1 estudados, os picos espectrais observados variaram entre $415-437 \mathrm{~nm}$.

Estudos feitos com primatas do Novo Mundo, humanos e uma espécie de primata do Velho Mundo (Macaca fascicularis), tiveram suas sequências de aminoácidos e respectivos picos de absorção espectrais descritos e estão representados na Tabela 8, juntamente com os resultados encontrados para as espécies estudadas no presente trabalho (em negrito): Cebus apella. Brachyteles arachnoides, Lagothrix lagotricha, Alouatta caraya, Alouatta clamitans, Ateles belzebuth e Callithrix jacchus (Mollon, Bowmaker \& Jacobs, 1984; Bowmaker, Dartnall \& Mollon, 1979; Bowmaker, Jacobs \& Mollon, 1887; Travis et al., 1988; Bowmaker, Astell, Hunt \& Mollon, 1991; Jacobs, 1996; Jacobs \& Deegan, 2001, 2003; Jacobs, Deegan II, Tan \& Li, 2003). 
Tabela 8. Principais aminoácidos responsáveis pela diferenciação do ultravioleta (UV) e do violeta (VS) e absorção espectral da opsina expressa pelo gene SWS1 de diferentes espécies de primatas do Novo Mundo, Velho Mundo e humanos.

\begin{tabular}{|c|c|c|c|c|}
\hline Gênero & Aminoácidos $^{1}$ & Método 2 & $\begin{array}{c}\text { Absorção } \\
\text { espectral (nm) }\end{array}$ & Referência \\
\hline Homo Sappiens & FLPGT & $\mathrm{ME}$ & 414 & Fasick, et al., 1999 \\
\hline Macaca fascicularis & FLPAT & $\mathrm{ME}$ & 415 & Bowmaker et al., 1979 \\
\hline Saimiri sciureus & (A) LLPGT & ME & 430 & Bowmaker et al., 1987 \\
\hline Callithrix Jacchus & (I) LLPGT & G/I/ ME & 423 & Presente trabalho / Travis et al., 1988 \\
\hline Cebus apella & (V) LLPAT & G/I/ERG & $425-427$ & Presente trabalho / Jacobs \& Deegan, 2002 \\
\hline Lagothrix lagotricha & (A) LLPAT & G/I/ERG & $432-437$ & Presente trabalho / Jacobs \& Deegan, 2001 \\
\hline Ateles geoffryi & (A) LLPAT & ERG & 432 & Jacobs \& Deegan, 2001 \\
\hline Ateles fusciceps & (A) LLPAT & ERG & 432 & Jacobs \& Deegan, 2001 \\
\hline Ateles belzebuth & (A) LLPAT & G/ I & $432-437$ & Presente trabalho \\
\hline $\begin{array}{l}\text { Brachyteles } \\
\text { arachnoides }\end{array}$ & (A) LLPAT & G/ I & $432-437$ & Presente trabalho \\
\hline Alouatta caraya & (A) LLPGT & G / I & 430 & Presente trabalho \\
\hline Alouatta clamitans & (A) LLPGT & G / I & 430 & Presente trabalho \\
\hline
\end{tabular}

${ }^{1}$ Aminoácidos de importantes posições para diferenciação do UV e VS (52, 86, 93, 114 e 119), em parênteses aminoácidos encontrados na posição 50 da opsina. ${ }^{2} \mathrm{ERG}=$ eletrorretinografia; $\mathrm{ME}=$ microespectrofotometria; $\mathrm{G}=$ Análise Genética; $\mathrm{I}$ = inferência a partir de análises genéticas.

Os estudos do gene SWS1 mostraram que indivíduos dos gêneros Callithrix e Alouatta apresentam a sequência LLPGT, enquanto que os indivíduos do gênero Cebus, Brachyteles, Lagothrix, e Ateles apresentam a sequencia LLPAT. Outra diferença importante foi observada na posição 50, na qual em Callithrix apresentou o aminoácido Isoleucina e Cebus o aminoácido Valina, enquanto que o aminoácido Alanina foi encontrado nos demais gêneros.

A variação dos aminoácidos LLPAT observada em C. apella, L. lagotricha, A. belzebuth e $B$. arachnoides, em posições importantes $(52,86,93,114$ e 118) para a diferenciação do ultravioleta (UV) e do violeta (VS) não havia sido descrita anteriormente para essas espécies. Apesar desta combinação de aminoácidos nestas quatro espécies não diferir, os picos de absorção espectral inferidos para estes grupos é 
diferente. Em Cebus, o pico de absorção espectral do pigmento expresso pelo gene SWS1 foi inferido em 425-427nm e as demais espécies em 432-437 nm. Este deslocamento em direção ao UV observado em Cebus a pode ser devido à substituição do aminoácido alanina pela valina na posição 50, resultando em um deslocamento no pico entre 5-10 nm, uma vez que este aminoácido está presente em pigmentos expressos pelo gene SWS1 com pico de absorção espectral no UV, assim como encontrado em camundongos (Shi \& Yokoyama, 2003). Outro fato que contribui para a importância da posição 50 no deslocamento do pico de absorção da opsina $S$ em direção ao UV é o observado em Callithrix. Neste gênero o pico de absorção espectral também pode estar sendo deslocado em direção ao UV devido à substituição da Alanina pela Isoleucina na posição 50 (Travis et al., 1988).

Indivíduos do gênero Callithrix apresentaram a mesma sequência de aminoácidos de Saimiri e Alouatta (LLPGT) nas posições importantes para diferenciação do UV e do VS. Entretanto, eles apresentam diferenças no pico de absorção espectral da opsina. Esta diferença também pode ser devida a substituição do aminoácido alanina pelo aminoácido isoleucina na posição 50. Assim como observado em Cebus, a substituição da alanina na posição 50 pode contribuir para o deslocamento do pico de sensibilidade espectral em direção ao ultravioleta. E em Callithrix, que possui uma isoleucina nesta posição, o pico de absorção espectral deve ocorrer em torno de 423 nm, uma diferença de 7 nm no pico em direção ao UV (Travis et al., 1988).

O gene SWS1 das duas espécies do gênero Alouatta ainda não tinha sido analisado anteriormente e apresentou a mesma sequência de aminoácidos encontrada em Saimiri boliviensis tanto para a sequência LLPGT quanto para a posição 50 (alanina). Em S. boliviensis, o pico de absorção espectral já havia sido previamente descrita por 
Bowmaker et al. (1987), sendo possível fazer a inferência do pico de absorção em Alouatta em 430nm.

Em Ateles belzebuth e Brachyteles arachnoides, que possuem a sequência de aminoácidos LLPAT e alanina na posição 50, o pico de absorção espectral foi inferido em 432 - 437 nm, assim como ocorre em espécies de Ateles e Lagothrix, devido a estes apresentarem a mesma sequência de aminoácidos e seus picos de absorção espectral já terem sidos descritos anteriormente (Jacobs \& Deegan 2001).

\subsection{Gene LWS/MWS}

No gene LWS/MWS o pico de absorção espectral das opsinas é determinado principalmente por três aminoácidos localizados nos sítios 180, 277 e 285, expressos pelos éxons 3 e 5. Os alelos responsáveis pela expressão dos pigmentos encontrados nos cones L e M são atualmente classificados em cinco tipos em primatas do Novo Mundo: AFA com pico de absorção espectral em 530 nm, AYA, com pico em 538 nm, AFT com pico em $545 \mathrm{~nm}$, AYT com pico em $553 \mathrm{~nm}$ e SYT com pico em $560 \mathrm{~nm}$ (Yokoyama and Radlwimmer, 2001; Hiramatsu et al., 2005). A combinação desses aminoácidos é responsável pela mudança no pico de sensibilidade espectral das opsinas, a qual é cumulativa, ou seja, cada substituição de determinados aminoácidos presentes na opsina pode deslocar o pico de absorção espectral desta (Hunt et al., 1998). Com isso, podemos inferir a curva de absorbância do fotopigmento através da combinação dos aminoácidos presentes nessas posições (Asenjo et al., 1994).

No presente trabalho verificou-se a presença de cinco alelos diferentes (SFT, SYT, SYA, AYA e AYT) nos 35 indivíduos analisados da espécie Callithrix jacchus. 
Os alelos SFT e SYA ainda não haviam sido descritos em Callithrix jacchus. O alelo (SFT) expressa uma opsina com pico de absorção espectral entre 546-553. É possível que este alelo não tenha sido identificado em estudos anteriores devido à semelhança em relação ao pico de absorção espectral do pigmento expresso pelo alelo AYT, o qual ocorre em 553 nm. Não foi encontrada descrição do pico de absorção espectral determinado pelo SYA na literatura. Com isso não foi possível estimar o pico de absorção espectral para os indivíduos que apresentaram essa sequência de aminoácidos.

Em estudos prévios, apenas três alelos foram descritos em espécies do gênero Callithrix: AYA com pico de absorção espectral em 538 nm, AYT, com pico em 553 nm e SYT com pico em 560 nm (Travis et al., 1988; Tovée et al., 1992; Shyue et al., 1998; Kawamura et al., 2001; Hiramatsu et al., 2005). Portanto este trabalho descreve pela primeira vez a presença dos alelos SFT e SYA nesta espécie, totalizando cinco possibilidades alélicas para o gene LWS/MWS em Callithrix jacchus.

As sequências de aminoácidos encontradas em Callithrix mostram que algumas fêmeas e machos apresentam uma variedade de alelos compatíveis com uma visão de cor tricromata. No caso das fêmeas heterozigotas, esse fenótipo é esperado, porém, machos heterozigotos dicromatas e heterozigotos tricromatas não correspondem ao esperado para os primatas do Novo Mundo. Uma explicação para a heterozigozidade encontrada em alguns machos é o quimerismo frequente nas espécies do gênero Callithrix. Indivíduos com linhagens celulares $\mathrm{XX} / \mathrm{XY}$ podem ocorrer devido à alta frequência de nascimentos gemelares com a troca de células sanguíneas entre os fetos (Benirschkle et al., 1962; Nagamachi et al., 1990).

Este quimerismo parece estar ausente ou em baixas quantidades em tecidos não hematopoiéticos (Signer et al., 2000). Em um estudo usando o DNA de sangue de 
Callithrix, todos os três indivíduos estudados mostraram sinais de hibridização para os alelos AYT e SYT. Ao utilizar amostras não sanguíneas os resultados mostram apenas um alelo para cada individuo (Kawamura, Hirai, Takenaka, Radlwimmer \& Yokoyama, 2001). Apesar disso, as amostras de fezes e pelo que foram utilizadas neste estudo, apresentaram grandes quantidades de quimerismo. Com isso, mais pesquisas são necessárias para elucidar os resultados encontrados em Callithrix.

Comparando os resultados da análise genética do gene LWS/MWS encontrados em Callithrix com outros grupos, observa-se que a variabilidade de 5 alelos também foi observada somente para Cebus. Para os demais grupos Lagothrix lagotricha, Ateles belzebuth, Brachyteles arachnoides e Alouatta (A. clamitans e A. caraya) houve pouca variação alélica no gene LWS/MWS.

Em Cebus foram descritas cinco diferentes combinações de aminoácidos: SYT, AYT, AFA, AFT e SFT (Tabela 9) (Bonci, 2012; Soares et al., 2010). Comparando esses dados com o de Callithrix observa-se que os alelos AFA e AYT presentes em macaco-prego, não foram encontrados nos saguis analisados neste trabalho. 
Tabela 9. Posições dos aminoácidos encontrados em indivíduos da espécie Cebus apella. Modificado de Bonci, 2012.

\begin{tabular}{|c|c|c|c|c|c|}
\hline \multicolumn{6}{|c|}{ Cebus apella } \\
\hline $\operatorname{Sexo}(N)$ & Alelo1 & Alelo 2 & $\max K 1$ & $\max \kappa 2$ & Fenótipo \\
\hline M (12) & SYT & & $560-563$ & & dicromata \\
\hline M (4) & AFA & & 532 & & dicromata \\
\hline M (3) & AFT & & $542-547$ & & dicromata \\
\hline M (2) & AYT & & $550-556$ & & dicromata \\
\hline $\mathrm{F}(5)$ & SYT & & $560-563$ & & dicromata \\
\hline $\mathrm{F}(3)$ & SFT & SYT & $546-553$ & $560-563$ & tricromata \\
\hline $\mathrm{F}(1)$ & AFT & & $542-547$ & & dicromata \\
\hline$F(2)$ & AFT & AFA & $542-547$ & 532 & tricromata \\
\hline
\end{tabular}

$\mathrm{M}=$ macho; $\mathrm{F}=$ fêmea; $\mathrm{N}=$ número de indivíduos que apresentaram o mesmo resultado; $\mathrm{S}=$ serina; $\mathrm{Y}=$ tirosina; $\mathrm{T}=$ treonina; $\mathrm{A}=$ alanina $; \mathrm{F}=$ fenilalanina $; \operatorname{lmax}=$ sensibilidade espectral máxima.

Nas duas espécies de Alouatta (A. clamitans e A. caraya) os resultados genéticos estão de acordo com um fenótipo tricromata para os seis indivíduos analisados, conforme o esperado na literatura (Jacobs, 1996). Entretanto os alelos não puderam ser identificados e assim o pico de absorção espectral não pôde ser identificado nesse caso. Nas demais espécies Lagothrix lagotricha, Ateles belzebuth e Brachyteles arachnoides foi encontrado apenas um alelo (SYT) (dados obtidos por D. Bonci, ainda não publicados) (Tabela 10). Os dados completos do sequenciamento encontram-se no Anexo 2. 
Tabela 10. Posições dos aminoácidos encontrados nas diferentes espécies estudadas da Família Atelidae (Bonci, comunicação pessoal)

\begin{tabular}{|c|c|c|c|c|c|}
\hline \multicolumn{6}{|c|}{ Família Atelidae } \\
\hline Espécie & $\operatorname{Sexo}(\mathbf{N})$ & Alelo 1 & Alelo 2 & $\max \lambda$ & Fenótipo \\
\hline \multirow{2}{*}{ Brachyteles arachnoides } & $\mathrm{M}(5)$ & SYT & & $560-563$ & Dicromata \\
\hline & $\mathrm{F}(1)$ & SYT & & $560-563$ & Dicromata \\
\hline \multirow{2}{*}{ Lagothrix lagotricha } & $\mathrm{M}$ & SYT & & $560-563$ & Dicromata \\
\hline & $\mathrm{F}$ & ND & ND & ND & Tricromata \\
\hline \multirow{3}{*}{ Alouatta clamitans } & $\mathrm{M}(2)$ & ND & ND & ND & Tricromata \\
\hline & $F(2)$ & ND & ND & ND & Tricromata \\
\hline & $\mathrm{M}(1)$ & ND & ND & ND & Tricromata \\
\hline \multirow{3}{*}{ Alouatta caraya } & $\mathrm{F}(1)$ & ND & ND & ND & Tricromata \\
\hline & M (1) & ND & ND & ND & Tricromata \\
\hline & $\mathrm{M}(1)$ & ND & ND & ND & Tricromata \\
\hline \multirow{2}{*}{ Ateles belzebuth } & $\mathrm{M}(1)$ & SYT & & $560-563$ & Dicromata \\
\hline & $F(3)$ & SYT & & $560-563$ & Dicromata \\
\hline
\end{tabular}

$\mathrm{M}=$ macho; $\mathrm{F}=$ fêmea; $\mathrm{N}=$ número de indivíduos que apresentaram o mesmo resultado; $\mathrm{S}=$ serina $; \mathrm{Y}=$ tirosina; $\mathrm{T}=$ treonina $; \lambda \max =$ sensibilidade espectral máxima. $\mathrm{ND}=$ não determinado.

Segundo Jacobs \& Deegan, 2001, no gênero Lagothrix estão presentes dois tipos de pigmentos com pico de absorção espectral em 545 nm (AFT) e $560 \mathrm{~nm}$ (SYT). Devido ao número restrito de indivíduos analisados $(\mathrm{N}=2)$, no qual um macho apresentou fenótipo dicromata e uma fêmea apresentou fenótipo tricromata, foi encontrado apenas um alelo (SYT), este com pico de absorção espectral entre 560 e 563 nm (Hiramatsu et al., 2005). Jacobs \& Deegan, 2001, também descrevem os dois tipos de pigmentos encontrados em Lagothrix para indivíduos do gênero Ateles (AFT e SYT). Entretanto nas espécies Ateles belzebuth foi encontrado apenas um alelo com pico em 560 e $563 \mathrm{~nm}(\mathrm{SYT})$.

O alelo SYT também foi o único encontrado nos indivíduos analisados da espécie Brachyteles arachnoides. Novamente é provável que somente um único alelo tenha sido descrito nestes animais devido ao número pequeno de indivíduos analisados 
( $\mathrm{N}=4$ para Ateles e $\mathrm{N}=5$ para Brachyteles) e apenas uma fêmea hetetozigota (ver Anexo 3), tornando baixa a ocorrência de outros alelos possíveis de serem encontrados nessas espécies. Na Tabela 11 estão representados os alelos encontrados juntamente com os picos de absorção espectral inferidos para todos os indivíduos analisados:

Tabela 11. Diferentes alelos encontrados em algumas espécies de primatas do Novo Mundo.

\begin{tabular}{ccc}
\hline Espécies & Alelos & $\begin{array}{c}\text { Pico de absorção espectral } \\
(\mathbf{n m})\end{array}$ \\
\hline Cebus apella & SYT; AYT; AFA; AFT e & $\begin{array}{c}560-563 ; 550-556 ; 532 ; 542- \\
547 \text { e 546-553 }\end{array}$ \\
\hline Srachyteles arachnoides & SYT & $560-563$ \\
\hline Lagothrix lagotricha & SYT & $560-563$ \\
\hline $\begin{array}{c}\text { Alouatta clamitans e A. } \\
\text { caraya }\end{array}$ & ND & ND \\
\hline Ateles belzebuth & SYT & $560-563$ \\
\hline Callithrix jacchus & SFT, SYT, AYA, AYT e & $\begin{array}{c}538,546-553,550-556 \mathrm{e} \\
560-563\end{array}$ \\
\hline
\end{tabular}

As curvas de sensibilidade espectral encontrados nos indivíduos dos gêneros Alouatta, Ateles, Brachyteles, Lagothrix, Callithrix e Cebus estão representadas na Figura 14. 



Figura 14. Curvas de sensibilidade espectral previstas a partir das sequências de aminoácidos dos pigmentos S, L e M para os cones de Alouatta, Ateles, Brachyteles, Lagothrix, Callithrix e Cebus. Gráficos elaborados pelo Dr. Balázs Vince Nagy baseado em Stockman \& Sharpe (2000).

Foram preenchidas várias lacunas na literatura acerca da variabilidade alélica dos genes que expressam as opsinas em primatas do Novo Mundo. Na Tabela 10 estão indicados em negrito as contribuições deste trabalho para a literatura da área. 
Tabela 12. Resumo dos trabalhos publicados que descrevem o pico de sensibilidade espectral das opsinas em algumas espécies de Primatas do Novo Mundo incluindo o presente trabalho.

\begin{tabular}{|c|c|c|c|c|c|c|c|c|}
\hline \multirow{2}{*}{$\begin{array}{c}\text { Família } \\
\text { Atelidae }\end{array}$} & \multirow{3}{*}{$\begin{array}{c}\text { Gênero } \\
\text { Ateles }\end{array}$} & \multirow{3}{*}{$\begin{array}{c}\lambda \underset{\mathbf{m a x}}{\mathbf{S}} \\
432\end{array}$} & \multicolumn{5}{|c|}{$\lambda \max \mathbf{L} / \mathbf{M}$} & \multirow{3}{*}{$\begin{array}{c}\text { Referências* } \\
\text { cobs \& Deegan II, 2000/2001; } \\
\text { (ERG). }\end{array}$} \\
\hline & & & & & & 550 & 561 & \\
\hline & & & & & 547 & & 562 & \\
\hline & & & & & & 553 & & Hiramatsu et al., 2008; (E). \\
\hline & & 432-437 & & & & & & Presente trabalho \\
\hline & Brachyteles & & 530 & & & 550 & 562 & Talebi et al., 2006; (I). \\
\hline & & 432-437 & & & & & & Presente trabalho \\
\hline & Lagothrix & 437 & & & 547 & & 562 & Jacobs \& Deegan II, 2001; (ERG). \\
\hline & & & 530 & & & & 562 & Jacobs et al., 1996; (ERG, I). \\
\hline & & 437 & & & & & & Presente trabalho \\
\hline & Alouatta & & 529 & & & 557 & & Saito et al., 2004; (SUER, MSP). \\
\hline & & & 532 & & & & 564 & Matsushita et al., 2014 (ERG) \\
\hline & & & 530 & & & & 562 & Yokoyama et al., 2008 (ERG) \\
\hline & & 423-430 & & & & & & Presente trabalho \\
\hline \multirow[t]{4}{*}{ Pitheciidae } & Pithecia & & & 537 & & & $563-565$ & $\begin{array}{l}\text { Jacobs \& Deegan II, 2000/2003; } \\
\text { (ERG). }\end{array}$ \\
\hline & 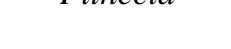 & & & 535 & & 550 & 562 & Boissinot et al., 1998; (I). \\
\hline & Callicebus & & 530 & 535 & 542 & 550 & 562 & Jacobs \& Deegan, 2005; (ERG). \\
\hline & & & & 535 & & 550 & 562 & Bunce et al., 2011; (I). \\
\hline \multirow[t]{23}{*}{ Cebidae } & & $425-427$ & & 534 & & & & Bowmaker et al., 1983; (MPS). \\
\hline & & & & 536 & 549 & & 561 & Jacobs \& Neitz, 1987b; (ERG). \\
\hline & & & 530 & & 545 & & & Saito et al., 2005; (E). \\
\hline & Cebus & & 532 & & 545 & 550 & 560 & Soares et al., 2010; (ERG, I). \\
\hline & & & & 535 & & & 563 & Lee et al., 1996; (SUER, I). \\
\hline & & & & 535 & & 550 & 563 & Lee et al., 2000; (SUER, MSP). \\
\hline & & & & 535 & & & 563 & Saito et al., 2001; (SUER). \\
\hline & & & & & 543 & & & Hiramatsu et al., 2005; (E). \\
\hline & & $425-427$ & & & & & & Jacobs \& Deegan, 2002 \\
\hline & & 425-427 & & & & & & Presente trabalho \\
\hline & & 430 & & 537 & & 550 & 565 & $\begin{array}{l}\text { Bowmaker et al., 1987/ Mollon et al., } \\
\text { 1984; (MSP). }\end{array}$ \\
\hline & Saimiri & & 532 & & 545 & 558 & & Hiramatsu et al., 2004; (E). \\
\hline & & & & 536 & 548 & & 561 & Jacobs \& Deegan II, 2003 (ERG). \\
\hline & & & & 538 & & 551 & 561 & Jacobs \& Neitz, 1987; (ERG). \\
\hline & Saguinus & & & & 545 & 557 & 563 & Jacobs \& Deegan II, 2003 (ERG). \\
\hline & Leontopithecus & & & & 545 & 557 & & Jacobs \& Deegan II, 2003 (ERG). \\
\hline & Callimico & & & & 543 & & 563 & Surridge \& Mundy, 2002; (I). \\
\hline & & 423 & & & 543 & 556 & 563 & Travis et al., 1981/1988; (MSP). \\
\hline & Callithrix & & & 539 & & 553 & 561 & Hiramatsu et al., 2004; (E). \\
\hline & & & & & 543 & & 563 & Yeh et al., 1995; (ERG). \\
\hline & & & & 539 & & 553 & 561 & Kawamura et al., 2001 (E) \\
\hline & & & & & 545 & 559 & 567 & Travis et al., 1988 (MPS) \\
\hline & & & & & 543 & 556 & 563 & Tovée et al., 1992 (MPS) \\
\hline
\end{tabular}




\section{Presente trabalho}

Surridge \& Mundy, 2002; (I).

Jacobs et al., 1993; (ERG, I, P).

Saito et al., 2001; (SUER)

*ERG = eletrorretinografia; $\mathrm{MSP}=$ microespectrofotometria $; \mathrm{E}=$ medidas in vitro da expressão dos cones; $\mathrm{I}$ = inferência a partir de análises genéticas; $\mathrm{P}=$ psicofísica; SUER = gravação extracelular única unidade.

\subsection{Opsinas e comportamento}

As implicações das mudanças no pico de absorção espectral do gene SWS1 em direção ao UV ou VS no comportamento dos primatas ainda não são conhecidas. Estudos com abelhas mostram que a percepção no UV desempenha um papel essencial na discriminação e percepção de flores (Dyer e Chittka, 2004). As abelhas também usam a percepção UV para se orientar de volta à colmeia de acordo com os raios solares, que servem de referência ao inseto (Moller, 2002). Em uma pesquisa com serpentes diurnas e noturnas, Hauzman, 2014 verificou que a densidade de cones L/M na retina foi semelhante nos dois grupos, porém a densidade de cones $\mathrm{S}$, que nessas espécies apresentam pico de absorção espectral no UV, foi mais alta em serpentes noturnas, fator que pode estar relacionado com o tipo de presa e estratégias reprodutivas nas diferentes espécies.

Em um estudo comparativo com Alouatta guariba e Brachyteles arachnoides, Martins (2008), verificou que em termos de dieta estes grupos apresentaram semelhanças e diferenças. Uma diferença é que a espécie de Alouatta consume mais frutas marrons e pretas e menos frutas de coloração violeta comparada com Brachyteles. Entretanto, esses resultados segundo o autor não são suficientes para indicar uma diferença na percepção de cores de cada espécie, mas sim como indicador de que esse 
tipo de exploração funcionaria como um mediador de recursos para a coexistência das espécies (Gautier-Hion, 1980; Terborgh, 1983; Peres, 1994; Stevenson et al., 2000).

São necessários estudos comportamentais para esclarecer se primatas que apresentaram o pico de absorção espectral em direção ao UV possuem uma percepção diferenciada comparada aos animais que apresentaram o pico em direção ao VS.

Em relação ao gene LWS/MWS os diferentes fenótipos de visão de cores podem afetar o comportamento desses animais. Em um estudo com Alouatta guariba e Brachyteles arachnoides feitos por Martins (2008), foi observado que A. guariba, consumiu significativamente mais frutas com coloração amarelo / laranja do que $B$. arachnoides, mas o autor não acredita que a diferente capacidade de detecção de cores possa explicar esse resultado, para ele a capacidade apresentada por Alouatta na detecção visual de frutos maduros em longas distancias é maior, devido a sua tricromacia, entretanto a heterozigozidade presente em algumas fêmeas de Brachyteles pode ajudar todo o grupo na detecção do alimento.

Ainda não se sabe ao certo o porquê da diferença da gama de cores que podem ser discriminadas entre os primatas, mas atualmente sabe se que as diferenças biogeográficas entre continentes, o tipo e a oferta de alimentos da vegetação e a dieta do individuo, na qual o grau de dependência de frutos, folhas e insetos podem variar (Dominy et al., 2003; Melin et al., 2007).

Mais estudos acerca dos genes das opsinas expressas em cones, assim como análises de microespectofotometria e observações comportamentais visuais são necessários para elucidar as forças evolutivas que atuam no polimorfismo da visão de cores em platyrrhinos e tricromacia uniforme em catarrhinos. Para um melhor entendimento da variedade de cores que podem ser discriminadas entre os primatas do 
Novo Mundo, é necessário relacionar o fenótipo e o genótipo desses animais. Várias análises genéticas foram realizadas com diferentes espécies, entretanto, poucos testes comportamentais utilizados para avaliar a discriminação de cores em primatas foram realizados até o momento (Saito et al., 2005).

Apesar de existirem alguns trabalhos comportamentais de visão de cores, relacionados principalmente a alimentação, ainda não se sabe ao certo se esse polimorfismo visual pode influenciar significativamente o comportamento desses animais (Vorobyev 2004; Melin, Fediganet, Hiramatsu \& Kawamura, 2008; Tovée, Bowmaker \& Mollon, 1992). Conhecer mais sobre a visão desses animais pode fornecer uma compreensão mais profunda do seu comportamento. 


\section{Conclusão}

As espécies C. apella, L. lagotricha, A. belzebuth e B. arachnoides apresentam a sequência de aminoácidos LLPAT no gene SWS1, com picos de sensibilidade espectral em 425-427 nm para o primeiro e 432-437 nm nos demais;

As espécies $C$. jacchus, A. caraya e A. clamitans apresentaram a sequência de aminoácidos LLPGT no gene SWS1, com picos de sensibilidade espectral em $423 \mathrm{~nm}$ para o primeiro e $430 \mathrm{~nm}$ para os demais;

Foi visto pela primeira vez que variações de aminoácidos na posição 50 do gene SWS1 em primatas do Novo Mundo podem contribuir na determinação do pico de absorção espectral dos pigmentos expressos por este gene.

Dois novos alelos (SFT e SYA) foram descritos para os genes LWS/MWS em Callithrix jacchus. 


\section{Referências Bibliográficas}

Alfaro, J. W. L., Silva, J. D. S. E., Rylands, A. B. (2012). How different are robust and gracile capuchin monkeys? An argument for the use of Sapajus and Cebus. American Journal of Primatology, 74(4): 273-286.

Asenjo, A. B., Rim, J., Oprian, D. D. (1994). Molecular determinants of human red/green color discrimination. Neuron, 12: 1131-1138.

Barros, P. K. S. \& Pessoa, D. M. A. (2012). Ecologia sensorial de primatas: a importância da visão de cores. O ecologia Australis, 16: 265-282.

Bear, M. F., Connors, B. W., Paradiso, M. A. (2002). Neurociências. Desvendando o sistema nervoso. P. 309. ArtMed. São Paulo.

Benirschke, K., Brownnhill, L., Hioefnagel, D., \& Allen, F. H., Jil. (1962). Langdon Down anomaly (mongolism) with 21/21 translocation and Klinefelter's syndrome in the same sibship. Cytogenetics, 1: 75.

Boissinot, S., Tan, Y., Shyue, S. K., Schneider, H., Sampaio, I., Neiswanger, K., Li, W. H. (1998). Origins and antiquity of X-linked triallelic color vision systems in New World monkeys. Proceedings of the National Academy of Sciences of the United States of America, 95(23), 13749-13754.

Bonci, D. M. O. (2011). Estudo dos pigmentos visuais de macaco-prego (Cebus $s p$ ) e da relação entre aspectos psicofísicos e a genéticos da visão de cores em humanos. Tese de Doutorado. Instituto de Psicologia. Universidade de São Paulo.

Bowmaker, J. K. (1991). The evolution of Vertebrate Visual Pigments and Photoreceptors. In J. Cronly-Dillon, \& R. L. Gregory, R. L. (Eds). Vision and Visual Dysfunction, 2: 63-81.

Bowmaker, J. K., Astell, S., Hunt, D. M. \& Mollon, J. D. (1991). Photosensitive and photostable pigments in the retinae of Old World monkeys. J. Exp. Biol., 156: 1-19. 
Bowmaker, J. K., Mollon, J. D., \& Jacobs, G. H. (1983). Microspectrophotometric measurements of Old and New world species of monkeys. In J. D. Mollon, \& L. T. Sharpe (Eds.), Colour vision: physiology and psychophysics (pp. 56-68). London: Academic Press.

Bowmaker, J.K., Dartnall, H.A.J. \& Mollon, J.D. (1979). The violet-sensitive receptors of primate retinae. J Physiol. 292: 31P.

Bowmaker, J.K., Jacobs, G.H., Mollon, J.D. (1987). Polymorphism of photopigments in the squirrel monkey: a sixth phenotype. Proc R Soc Lond B Biol Sci., 231(1264): 383-390.

Bradley, B.J. \& Mundy, N.I. (2008). The Primate Palette: The Evolution of Primate Coloration.Evolutionary Anthropology, 17: 97-111.

Brown, P.K. \& Wald, G. (1963). Visual pigments in human and monkey retinas. Nature (London), 200: 37-43.

Buchanan-Smith, H.M. (2005). Recent advances in color vision research. Am. J. Primatol., 67: 393-398.

Bunce, J. A., Isbell, L. A., Neitz, M., Bonci, D., Surridge, A. K., Jacobs, G. H., \& Smith, D. G. (2011). Characterization of opsin gene alleles affecting color vision in a wild population of titimonkeys (Callicebus brunneus). American Journal of Primatology, 73(2): 189-196.

Burns, M. E. \& Lamb, T. D. (2003). Visual transduction by rod and cone photoreceptors. Center for Neuroscience and Department of Psychiatry, University of California, Davis, CA, and Physiological Laboratory, University of Cambridge, Cambridge, CB2 3EG, UK.

Caine, N. G. \& Mundy, N. I. (2000). Demosnstration of a foraging a dvantage for trichromatic marmosets (Callithrix geoffroyi) dependent on food colour. Biol Lett., 6(1): $36-38$.

Cajal, S. (1893). La rétine des vertébrés. Cellule 9, 121-255. 
Calderone, J. B. \& Jacobs, G. H. (1999). Cone receptor variations and their functional consequences in two species of hamster. Vis. Neurosci., 16: 53-63.

Calkins, D.J., Tsukamoto, Y., Sterling. P. (1998). Microcircuitry and mosaic of a blue-yellow ganglion cell in the primate retina. Journal of Neuroscience, 18: 33733385.

Caro, T. (2005). The adaptive significance of coloration in mammals. Bioscience, 55: 125-136.

Cowing, J. A., Poopala-sundaram, S., Wilkie, S. E., Robinson, P. R., Bowmaker, J. K. \& Hunt, D. M. (2002). The molecular mechanism for the spectral shifts between vertebrate ultraviolet- and violet-sensitive cone visual pigments. Biochem. J. 367: $129-135$.

De Valois, R. L. (1965). Analysis and Coding of Color Vision in the Primate Visual System. Cold Spring Harb Symp Quant Biol, 30, 567-579.

Deeb, S. S. (2005). The molecular basis of variation in human Colour vision. Clinical Genetics, 67(5): 369-377.

Defler, T. R. (2004). Primates of Colombia. Colombia: Conservation International. $550 \mathrm{p}$.

Dominy, N. J., Svenning, J. C., \& Li,W.-H. (2003). Historical contingency in the evolution of primate colorvision. Journal of Human Evolution, 44(1): 25-45.

Dowling, J. E. \& Boycott, B. B. (1966). Organization of the primate retina: Electron microscopy. Proc. R. Sot. Lond. [Biol.], 166: 80- 111.

Dyer, A.G. \& Chittka, L. (2004). Bumblebees (Bombus terrestris) sacrifice foraging speed to learn difficult colour discrimination tasks. Journal of Comparative Physiology A, 190: 759-763.

Euller, T., Wassle, H. (1995). Immunocytochemical identification of cone bipolar cells in the rat retina. J Comp Neurol., 365:461-78. 
Fasick, J. I., Lee, N. \& Oprian, D. D. (1999). Spectral tuning in the human blue cone pigment. Biochemistry, 38: 593-596.

Feagle, J.G. (1999). The primate bod: .14-17. In: Feagle J.G. (Ed.), Primate Adaptation and Evolution. 2nd ed. Academic Press, San Diego.

Fooden J., (1963). A revision of the wooly monkeys (genus Lagothrix). Journal of Mammalogy, 44(2): 213-247.

Fragaszy, D. M., Visalberghi, E. \& Fedigan, L. M. (2004). The Complete Capuchin: the Biology of the Genus Cebus. Cambridge.

Gautier-Hion, A. (1980). Seasonal variations of diet related to species and sex in a community of Cercopithecus monkeys. J Anim Ecol., 49: 237-269.

Gegenfurtner, K. R. \& Kiper, D. C. (2003). Color Vision. Annual Reviews of Neuroscience, 26: 181-206.

Ghosh, K.K., Martin, P.R., Grünert, U. (1997). Morphological analysis of the blue cone pathway in the retina of a New World monkey, the marmoset Callithrix jacchus. Journal of Comparative Neurology, 379: 211-225.

Goodman, M., Porter, C. A., Czelusniak, J., Page, S. L., Schneider, H., Shoshani, J., Groves, C. P. (1998). Toward a phylogenetic classification of primates based on DNA evidence complemented by fossil evidence. Molecular Phylogenetics and Evolution, 9(3): 585-598.

Gregorin, R. (2006). Taxonomia e variação geográfica das espécies do gênero Alouatta Lacépède (Primates, Atelidae) no Brasil. Revista Brasileira de Zoologia, 23(1): 64-144.

Groves, C. P. (2001). Primate taxonomy. Smithsonian Institution Press. Washington, DC.

Hargrave, P. A., \& McDowell, J. H. (1992). Rhodopsin and phototransduction. 
Hauzman, E. (2014). Ecologia e evolução do sistema visual de serpentes Caenophidia: estudos comparativos da morfologia retiniana e genética de opsinas. Tese de Doutorado. Instituto de Psicologia. Universidade de São Paulo.

Hendry, S.H. \& Reid, R.C. (2000). The koniocellular pathway in primate vision. Annu. Rev. Neurosci., 23: 127-53.

Hiramatsu, C., Melin, A.D., Aureli, F., Schaffner, C.M., Vorobyev, M., Matsumoto, Y., et al. (2008). Importance of achromatic contrast in short-range fruit foraging of primates. PLoS ONE, 3, e3356.

Hiramatsu, C., Tsutsui, T., Matsumoto, Y., Aureli, F., Fedigan, L. M., \& Kawamura, S. (2005). Color-vision polymorphism in wild capuchins (Cebus capucinus) and spider monkeys (Ateles geoffroyi) in Costa Rica. American Journal of Primatology, 67(4): 447-461.

Houle, A., Vickery, W.L., Chapman, C.A. (2006). Testing mechanisms of coexistence among two species of frugivorous primates. J Anim Ecol., 75: 10341044.

Hunt, D. M. \& Li, W. H. (1998). Molecular genetics of spectral tuning in New World monkey Colour vision. Journal of Molecular Evolution, 46: 697-702.

Hunt, D. M. \& Peichl, L. (2014). S cones: Evolution, retinal distribution, development, and spectral sensitivity. Visual Neuroscience, 31: 115-138.

Hunt, D. M., Carvalho, L., Cowing, J. A., Davies, W. (2009). Evolution and spectral tuning of visual pigments in birds and mammals. Philosophical Transactions of the Royal Society B: Biological Sciences, 364: 2941-2955.

Hunt, D. M., Dulai K. S., Cowing J. A., Julliot C., Mollon J. D., Bowmaker J. K., Li W. H., \& Hewett-Emmett D., (1998). Molecular evolution of trichromacy in primates. Vision Research 38: 3299 - 3306.

Iwai, L., Kawasaki, H. (2009). Molecular development of the lateral geniculate nucleus in the absence of retinal waves during the time of retinal axon eye-specific segregation. Neuroscience, 159, 1326-1337. 
Jacobs, G. H, Deegan II, J. F., Neitz, J., Crognale, M. A., Neitz, M. (1993).

Photopigments and Colour vision in the nocturnal monkey, Aotus. Vision Research, 33(13), 1773-1783.

Jacobs, G. H. \& Deegan II, J. F. (1999). Uniformity of colour vision in Old World Monkeys. Proceeding of the Royal Society of London, 266 B: 2023-2028.

Jacobs, G. H. (1996). Primate photopigment and primate color vision. Proceedings of the National Academy of Science, 93: 577-581.

Jacobs, G. H. (1998). A perspective on color vision in platyrrhine monkeys. Vision Res 38: 3307-3313.

Jacobs, G. H. (2007). New World Monkeys and Colour. International Journal of Primatology, 28: 729-759.

Jacobs, G. H. (2008). Primate Colour vision: a comparative perspective. Visual Neuroscience, 25(5-6): 619-633.

Jacobs, G. H., \& Deegan, J. F., 2nd (2001). Photopigments and color vision in New World monkeys from the family Atelidae. Proceedings, Biological Sciences, 268(1468): 695-702.

Jacobs, G. H., \& Deegan, J. F., 2nd (2005). Polymorphic New World monkeys with more than three M/L cone types. Journal of the Optical Society of America A: Optics, Image, Science and Vision, 22(10): 2072-2080.

Jacobs, G. H., \& Neitz, J. (1987a). Inheritance of color vision in a New World monkey (Saimiri sciureus). Proceedings of the National Academy of Sciences of the United States of America, 84(8): 2545-2549.

Jacobs, G. H., \& Neitz, J. (1987b). Polymorphism of the middle wavelength cone in two species of South American monkey: Cebus apella and Callicebus moloch.

Vision Research, 27(8): 1263-1268.

Jacobs, G.H., Deegan II, J.F. (2003). Cone pigment variations in four genera of New World monkeys. Vision Res., 43: 227-236. 
Jacobs, G.H., Deegan, II, J.F., Tan,Y., Li, W.H. (2002). Opsin gene and photopigment polymorphism in a prosimian primate. Vision Res, 42: 11-18.

Jerusalinsky, L., Talebi, M. e Mello, F. R. (Orgs.) (2011). Plano de Ação Nacional para a Conservação dos Muriquis. ICMBIO, Brasília.

Joselevitch, C.S., John M., Ventura, D. F. (2010). No evidence of UV cone input to mono- and biphasic horizontal cells in the goldfish retina. journal of comparative physiology a-neuroethology sensory neural and behavi, 196 (12): 913-925.

Kainz, P. M., Neitz, J., \& Neitz, M. (1998). Recent evolution of uniform trichromacy in a New World monkey. Vision Research, 38(21):.6 3315-3320.

Kawamura, S. (1993). Rhodopsin phosphorylation as a mechanism of cyclic GMP phopsphodiesterase regulation by S-modulin. Nature, 362: 855-857.

Kawamura, S., Hirai, M., Takenaka, O., Radlwimmer, F. B., \& Yokoyama, S. (2001). Genomic and spectral analyses of long to middle wavelength-sensitive visual pigments of common marmoset (Callithrix jacchus). Gene, 269(1-2): 45-51.

Kolb, H. (2003). How the Retina Works. American Scientist, 91: 28-35.

Kowalewski, M. M. \& Zunino, G. E. (1999). Impact of deforestation on a population of Alouatta caraya in northern Argentina. Folia Primatologica, 70(3): $163-166$.

Lam, K., Sefton, A,J., Bennett, M.R. (1982). Loss of axons from the optic nerve of the rat during early postnatal development. Brain Res., 255(3): 487-91.

Lamb, T. D., Collin, S., \& Pugh, E. N. (2007). Evolution of the vertebrate eye: opsins, photoreceptors, retina and eye cup. Nature Reviews Neuroscience, 8: 960975.

Lee, B. B. (2004). Paths to colour in the retina. Clinical and Experimental Optometry 87: 239-248.

Lee, B. B., Silveira, L. C. L., Yamada, E. S., Hunt, D. M., Kremers, J., Martin, P. R., da Silva-Filho, M. (2000). Visual response of ganglion cells of a New-World 
primate, the capuchin monkey, Cebus apella. Journal of Physiology (London), 528(3): 573-590.

Lee, B. B., Silveira, L.C.L., Yamada, E.S., \& Kremers, J. (1996). Parallel pathways in the retina of Old and New World primates. Revista Brasileira de Biologia, 56 (Suppl. 1, Pt. 2): 323-338.

Leventhal, A.G., Rodieck, R.W., \& Dreher, B. (1981). Retinal ganglion cell classes in the Old World monkeys: Morphology and central projections. Science, 213: 1139-1142.

Lewis, B., Jurmain, R., Kilgore, L. (2012). Understanding Humans: An introduction to physical anthropology and archaeology. Wadsworth Publishing Co Inc; 11th Revised edition edition: 115-144.

Livingstone, M.S. \& Hubel, D. H. (1987). Psychophysical evidence for separate channels for the perception of form, color, movement, and depth. The Journal of Neuroscience, 7: 3416-3468.

Lyon, M.F. (1962). Sex chromatin and gene action in the mammalian X chromosome. Am J Hum Genet, 14: 135-148.

Martins, M. M. (2008). Fruit diet of Alouatta guariba and Brachyteles arachnoides in Southeastern Brazil: comparison of fruit type, color, and seed size. Primates, 49: $1-8$.

Matsushita, Y., Oota, H., Welker, B.J., Pavelka, M.S., Kawamura, S. (2014). Color vision variation as evidenced by hybrid L/M opsin genes in wild populations of trichromatic Alouatta New World monkeys. Int J Primatol, 35: 71-87.

McBee, J. K., Palczewski, K., Baehr, W., \& Pepperberg, D. R. (2001) Confronting complexity: the interlink of phototransduction and retinoid metabolism in the vertebrate retina. Prog Retin Eye Res., 20(4): 469-529.

Melin, A. D., Fedigan, L. M., Hiramatsu, C., Sendall, C., \& Kawamura, S. (2007). Effects of colour vision phenotype on insect capture by a free-ranging population of white-faced capuchins (Cebus capucinus). Animal Behaviour, 73(1): 205-214. 
Melin, A. D., Fedigan, L.M., Hiramatsu, C. \& Kawamura, S. (2008). Polymorphic color vision in white-faced capuchins (Cebus capucinus): Is There foraging niche divergence among phenotypes: Behavioral Ecology and Sociobiology, 62: 659-670.

Mendez, A., Lem, J., Simon, M., Chen, J. (2003). Light-dependent translocation of arrestin in the absence of rhodopsin phosphorylation and transducin signaling. $\mathrm{J}$ Neurosci., 23(8): 3124-9.

Möller, R. (2002). Insects could exploit UV-green contrast for Landmark navigation. J. Theor. Biol., 214: 619-631.

Mollon, J. D. (1989). "Tho' she kneel'd in that place where they grew" The uses and origins of primate colour vision. J. Exp. Biol., 146: 21-38.

Mollon, J. D., Bowmaker, J. K. \& Jacobs, G. H. (1984). Variations of colour vision in a New World primate can be explained by polymorphism of retinal photopigments. Proc. R. Soc. Lond. B, 222: 373-399.

Morgan, M.J.; Adam, A. \& Mollon, J.D. (1992). Dichromats detect colour camouflaged objects that are not detected by trichromats. Proc. R. Soc. Lond. B, 248: 291-295.

Nagamachi, C.Y., Pieczarka, J.C. \& Barros, R.M.S. (1990). Cytogenetic study of Saguinus midas midas( Callithrichidae, Primates) from Jari, Brazilian Amazonia. Comparison with the karyotype of Saguinus midas niger. Rev. Bras. Genet., 13: 8996.

Nathans, J., Thomas, D., Hogness, D. S. (1986). Molecular genetics of human Colour vision: the genes encoding blue, green, and red pigments. Science, 11, 232(4747): 193- 202.

Neville, M. K., Glander, K. E., Braza, F. e Rylands, A. B. (1988). The howling monkeys, genus Alouatta. In: Ecology and Behavior of Neotropical Primates. Vol. 2, R. A. Mittermeier, A. B. Rylands, A. F. Coimbra-Filho e G. A. B. da Fonseca (eds.), p.349-453. World Wildlife Fund, Washington, DC. 
Penn, J.S., Williams, T.P. (1986). Photostasis: regulation of daily photon-catch by rat retinas in response to various cyclic illuminances. Exp Eye Res., 43(6): 915-28. Peres, C.A. (1994). Primate responses to phenological changes in an Amazonian terra firme forest. Biotropica, 26: 98-112.

Ross, C., French, J. \& Ortí, G. (2007). Germ Line Chimerism and Paternal Care in Marmosets (Callithrix kuhlii). Proc. Natl. Acad. Sci. USA, 104(15): 6278-6282.

Saari, J.C., Bredberg, D.L., Noy, N. (1994). Control of substrate flow at a branch in the visual cycle. Biochemistry, 33(10): 3106-12.

Saito, A., Kawamura, S., Mikami, A., Ueno, Y., Hiramatsu, C., Koida, K., Fujita, K., Kuroshima, H., \& Hasegawa, T. (2005). Demonstration of genotype-phenotype correlation in polymorphic color vision of a non-callitrichine New World monkey, capuchin (Cebus apella). American Journal of Primatology, 67: 471-485.

Saito, C. A., da Silva Filho, M., Lee, B. B., Bowmaker, J. K., Kremers, J., \& Silveira, L. C. L. (2004). Alouatta trichromatic color vision: Single-unit recording from retinal ganglion cells and microspectrophotometry. Investigative Ophthalmology \& Visual Science, 45(5): E-Abstract 4276-B737.

Saito, C. A., Lee, B. B., Kremers, J., Silveira, L. C. L., da Silva Filho, M., \& Kilavik, B. E. (2001). Rod-cone interactions in the ganglion cell response: Studies using the diurnal capuchin-monkey and the nocturnal owl-monkey. Investigative Ophthalmology \& Visual Science, 42(4): S676.

Schneeweis, D.M., Schnapf, J.L. (1995). Photovoltage of rods and cones in the macaque retina. Science, 268: 1053-1056.

Schneider, H. (2000). The current status of the New World Monkey phylogeny. Bragança: Academia Brasileira de Ciências, 72: 165-172.

Shi Y., \& Yokoyama S.. (2003). Molecular analysis of the evolutionary significance of ultraviolet vision in vertebrates. Proceedings of the National Academy of Sciences., 100: 8308-8313. 
Shyue, S. K., Boissinot, S., Schneider, H., Sampaio, I., Schneider, M. P. C., Abee, C. R., Williams, L., Emmett, D. H., Sperling, H. G., Cowing, J. A., Dulai, K. S.,

Signer, E.N., Anzenberger, G., Jeffreys, A.J. (2000). Chimaeric and constitutive DNA fingerprints in the common marmoset (Callithrix jacchus). Primates, 41: 4961.

Silveira, L. C. L., Saito, C. A., Da Silva Filho, M., Bowmaker, J. K., Kremers, J. \& Lee, B. B. (2007). Physiological properties of photoreceptors and retinal ganglion cells from a trichromatic platyrrhine: The howler monkey, Alouatta sp. In L. C. L.

Silveira, D. F. Ventura, \& B. B. Lee (Eds.), 19th Symposium of the International Colour Vision Society abstracts book (p. 69). Belém, Brazil: EDUFPA.

Soares, J. G., Fiorani, M., Araujo, E. A., Zana, Y., Bonci, D. M. O., Neitz, M., Ventura, D.F. \& Gattass, R. (2010). Cone photopigment variations in Cebus apella monkeys evidenced by electroretinogram measurements and genetic analysis. Vision Research, 50(1): 99-106.

Springer, M. S., Meredith, R. W., Gatesesy, J., Emerling, C. A., Park, J. Rabosky, D. L., Stadler, T., Steiner, C., Ryder, O. A. , Janečka, J. E., Fisher, C. A., Murphy, W. J. (2012) Macroevolutionary Dynamics and Historical Biogeography of Primate Diversification Inferred from a Species Supermatrix. PLoS ONE 7(11): e49521.

Sterling, O., Freed, M.A. \& Smith, R.G. (1988). Functional architecture of the rod and cone circuits to the on-beta ganglion cell. Journal of Neuroscience, 8: 623-42.

Stevenson, M. F., Rylands, A. B. (1988). The marmosets, genus Callithrix. In: Ecology and Behavior of Neotropical Primates, Vol. 2, Mitrermeier, R. A.; Rylands, A. B.; Coimbra-Filho, A. F.; Da Fonseca, G. A. B. (eds.), World Wildlife Fund, Washington DC, p. 131-222.

Stevenson, P.R., Quinõnes, M.J., Ahumada, J.A. (2000). Influence of fruit availability on ecological overlap among four neotropical primates at Tinigua National Park, Colombia. Biotropica, 32: 533-544. 
Stockman, A., \& Sharpe, L. T. (2000). The spectral sensitivities of the middle- and longwavelength-sensitive cones derived from measurements in observers of known genotype. Vision Research, 40(13): 1711-37.

Sumner, P. \& Mollon, J.D. (2000) Catarrhine photopigments are optimised for detecting targets against a foliage background. J. Exp. Biol., 203: 1963-1986.

Surridge, A. K., \& Mundy, N. I. (2002). Trans-specific evolution of opsin alleles and the maintenance of trichromatic colour vision in Callitrichine primates. Molecular Ecology, 11: 2157-2169.

Surridge, A. K., Osorio, D., Mundy, N. I., (2003). Evolution and selection of trichromatic color vision in primates. Trends in Ecology and Evolution, 18: 198205.

Szaley, F. S. \& Delson, E., (1979) Evolutionary History of the Primates. New York: Academic Press. Taylor, CR (1977) Why big animals? Cornell Vet., (67): 155-175.

Talebi, M. G., Pope, T. R., Vogel, E. R., Neitz, M., \& Dominy, N. J. (2006). Polymorphism of visual pigments in the muriqui (Primates, Atelidae). Molecular Ecology, 15: 551-558.

Talebi, M.; Bastos, A.; Lee, P. C., (2005). Diet of southern muriquis in continuous brazilian Atlantic Forest. International Journal of Primatology, New York, 26(5): 1175-1186.

Terborgh, J. (1983). Five new world primates, a study in comparative ecology. Princeton University Press, Princeton.

Tovée, M.J., Bowmaker, J.K., Mollon, J.D. (1992). The relationship between cone pigments and behavioural sensitivity in a New World monkey (Callithrix jacchus jacchus). Vision Research, 32: 867-878.

Travis, D. S., Bowmaker, J. K., Mollon, J. D. (1988). Polymorphism of visual pigments in a callitrichid monkey. Vision Res, 28: 481-490. 
Trezise, A. E. O. \& Collin, S. P. (2005). Opsins: evolution is waiting. Current Biology, 15(19): 794-196.

Van Roosmalen, M. G. M. (1985). Habitat preferences, diet, feeding strategy, and social organization of the black spider (Ateles paniscus paniscus Linnaeus 1758) in Surinam. Acta Amazonica, 15(3-4): 1-238.

Van Roosmalen, M. G. M.; Klein, L. L., (1988) The spider monkeys, genus Ateles. In: Mitter-Meier, A. (Ed.). Ecology and Behavior of Neotropical Primates, Washington: World Wildlife Fund., 2: 455-537.

Ventura, D. F., Zana, Y., Souza, J. M., De Voe R. D. (2001). Ultraviolet color opponency in the turtle retina. Journal of Experimental Biology, 204: 2527-2534.

Verhulst, S. \& Maes, F.W. (1998). Scotopic vision in colour blinds. Vision Res., 38: 3387-3390.

Vorobyev, M. (2004). Ecology and evolution of primate color vision. Clinical and Experimental Optometry, 87: 230-238.

Waitt, C., Little, A.C., Wolfensohn, S., Honess, P., Brown, A.P., Buchanan-Smith, H.M. \& Perrett, D.I. (2003). Evidence from rhesus macaques suggest that male coloration plays a role in female primate mate choice. Proceedings of the Royal Society of London Series B: Biological Sciences, 270: 144-146.

Wu, Q. Chen, C. Koutalos, Y. (2006). All-trans retinol in rod photoreceptor outer segments moves unrestrictedly by passive diffusion. Biophys J., 91(12): 4678-89.

Yeh, T., Lee, B. B., Kremers, J., Cowing, J. A., Hunt, D. M., Martin, P. R., \& Troy, J. B. (1995). Visual responses in the lateral geniculate nucleus of dichromatic and trichromatic marmosets (Callithrix jacchus). Journal of Neuroscience, 15: 78927904.

Yokoyama, S. (2002). Molecular evolution of color vision in vertebrates. Gene, 300: 69-78. 
Yokoyama, S., Yang, H. and Starmer, W. T. (2008) Molecular basis of spectral tuning in the red- and green-sensitive (M/LWS) pigments in vertebrates. Genetics, 179: 2037-2043.

Young, R.W. (1971). Shedding of discs from rod outer segments in the rhesus monkey. J Ultrastruct Res., 34(1): 190-203.

Zanon, C. M. V., Reis, N. R., Ortêncio Filho, H., (2008). Gênero Ateles E. Geoffroy 1806. In: Reis, N. R., Peracchi, A. L., Andrade, F. R. (organizadores). Primatas brasileiros. Londrina: Techinical Books. 169- 173. 


\section{ANEXOS}

ANEXO 1. Tabela completa com os dados do sequenciamento do gene LWS/MWS de Callithrix jacchus.

\begin{tabular}{|c|c|c|c|c|c|c|c|c|}
\hline \multicolumn{9}{|c|}{ Callithrix jacchus } \\
\hline \multirow{2}{*}{$\operatorname{Sexo}(N)$} & \multirow{2}{*}{$\begin{array}{c}\text { Exon } 3 \\
180\end{array}$} & \multicolumn{2}{|c|}{ Exon 5} & \multirow{2}{*}{ Alelo1 } & \multirow{2}{*}{ Alelo 2} & \multirow{2}{*}{$\max \mathbf{\Lambda 1}$} & \multirow{2}{*}{$\max \Lambda 2$} & \multirow{2}{*}{ Fenótipc } \\
\hline & & 277 & 285 & & & & & \\
\hline M (6) & $\begin{array}{c}\text { TCT } \\
\text { ser }\end{array}$ & $\begin{array}{c}\text { TAC/TAT } \\
\text { Tyr }\end{array}$ & $\begin{array}{c}\text { ACC } \\
\text { Thr }\end{array}$ & SYT & & $560-563$ & & dicromata \\
\hline M (5) & $\begin{array}{l}\text { TCT } \\
\text { Ser }\end{array}$ & $\begin{array}{c}\text { TAC } \\
\text { Tyr } \\
\end{array}$ & $\begin{array}{c}\text { ACC } \\
\text { Thr }\end{array}$ & SYT & & $560-563$ & & dicromata \\
\hline M (5) & $\begin{array}{l}\text { TCT } \\
\text { Ser }\end{array}$ & $\begin{array}{c}\text { TAC/TTC } \\
\text { Tyr/Phe }\end{array}$ & $\begin{array}{c}\text { ACC } \\
\text { Thr }\end{array}$ & SYT & SFT & $560-563$ & $546-553$ & tricromata \\
\hline M (1) & $\begin{array}{l}\text { TCT } \\
\text { Ser }\end{array}$ & $\begin{array}{l}\text { TTC } \\
\text { Phe }\end{array}$ & $\begin{array}{c}\text { ACC } \\
\text { Thr }\end{array}$ & SFT & & $546-553$ & & dicromata \\
\hline M (1) & $\begin{array}{c}\text { TCT } \\
\text { ser }\end{array}$ & $\begin{array}{l}\text { TAT } \\
\text { Tyr }\end{array}$ & $\begin{array}{c}\text { ACC } \\
\text { Thr }\end{array}$ & SYT & & $560-563$ & & dicromata \\
\hline $\mathrm{F}(4)$ & $\begin{array}{c}\text { TCT } \\
\text { ser }\end{array}$ & $\begin{array}{c}\text { TAC/TAT } \\
\text { Tyr }\end{array}$ & $\begin{array}{c}\text { ACC } \\
\text { Thr }\end{array}$ & SYT & & $560-563$ & & dicromata \\
\hline$F(3)$ & $\begin{array}{l}\text { TCT } \\
\text { Ser }\end{array}$ & $\begin{array}{c}\text { TAC/TTC } \\
\text { Tyr/Phe }\end{array}$ & $\begin{array}{c}\text { ACC } \\
\text { Thr }\end{array}$ & SYT & SFT & $560-563$ & $546-553$ & tricromata \\
\hline $\mathrm{F}(2)$ & $\begin{array}{l}\text { TCT } \\
\text { Ser }\end{array}$ & $\begin{array}{l}\text { TAC } \\
\text { Tyr }\end{array}$ & $\begin{array}{c}\text { ACC } \\
\text { Thr }\end{array}$ & SYT & & $560-563$ & & dicromata \\
\hline$F(2)$ & $\begin{array}{l}\text { TCT } \\
\text { Ser }\end{array}$ & $\begin{array}{c}\text { TAC/TTC } \\
\text { Tyr/Phe }\end{array}$ & $\begin{array}{c}\text { ACC/GCC } \\
\text { Thr/Ala }\end{array}$ & ND & ND & ND & ND & ND \\
\hline $\mathrm{F}(1)$ & $\begin{array}{l}\text { TCT } \\
\text { Ser }\end{array}$ & $\begin{array}{c}\text { TAC } \\
\text { Tyr }\end{array}$ & $\begin{array}{c}\text { ACC/GCC } \\
\text { Thr/Ala }\end{array}$ & SYT & SYA & $560-563$ & ND & ND \\
\hline $\mathrm{F}(1)$ & $\begin{array}{l}\text { TCT } \\
\text { Ser }\end{array}$ & $\begin{array}{c}\text { TAC/TAT } \\
\text { Tyr }\end{array}$ & $\begin{array}{c}\text { ACC/GCC } \\
\text { Thr/Ala }\end{array}$ & SYT & SYA & $560-563$ & ND & ND \\
\hline $\mathrm{F}(1)$ & $\begin{array}{c}\text { TCT } \\
\text { ser }\end{array}$ & $\begin{array}{c}\text { TAC } \\
\text { Tyr }\end{array}$ & $\begin{array}{c}\text { ACC } \\
\text { Thr }\end{array}$ & SYT & & $560-563$ & & dicromata \\
\hline $\mathrm{F}(1)$ & $\begin{array}{l}\text { GCT } \\
\text { Ala } \\
\end{array}$ & $\begin{array}{l}\text { TAT } \\
\text { Tyr }\end{array}$ & $\begin{array}{c}\text { ACC } \\
\text { Thr }\end{array}$ & AYT & & $550-556$ & & dicromata \\
\hline $\mathrm{F}(1)$ & $\begin{array}{c}\text { GCT } \\
\text { Ala } \\
\end{array}$ & $\begin{array}{c}\text { TAC } \\
\text { Tyr }\end{array}$ & $\begin{array}{c}\text { GCC } \\
\text { Ala } \\
\end{array}$ & AYA & & 538 & & dicromata \\
\hline$F(1)$ & $\begin{array}{c}\text { GCT/TCT } \\
\text { Ala/Ser }\end{array}$ & $\begin{array}{l}\text { TAC } \\
\text { Tyr }\end{array}$ & $\begin{array}{c}\text { ACC } \\
\text { Thr }\end{array}$ & SYT & AYT & $550-563$ & $550-556$ & tricromata \\
\hline
\end{tabular}

$\mathrm{M}=$ macho; $\mathrm{F}=$ fêmea; $\mathrm{N}=$ número de indivíduos que apresentaram o mesmo resultado; $\mathrm{S}=$ serina $; \mathrm{Y}=$ tirosina; $\mathrm{T}=$ treonina; $\mathrm{A}=$ alanina $\mathrm{F}=$ fenilalanina $\lambda \max =$ sensibilidade espectral máxima. ND = não determinado. 
ANEXO 3. Tabela completa com os dados do sequenciamento do gene LWS/MWS da Família Atelidae.

\begin{tabular}{|c|c|c|c|c|c|c|c|c|}
\hline Família Atelidae & & Exon 3 & $\mathbf{E x}$ & on 5 & & & & \\
\hline Espécie & $\operatorname{Sexo}(\mathbf{N})$ & 180 & 277 & 285 & Alelo1 & Alelo 2 & $\max \lambda$ & Fenótipo \\
\hline \multirow{2}{*}{$\begin{array}{l}\text { Brachyteles } \\
\text { arachnoides }\end{array}$} & M (5) & TCT (Ser) & $\begin{array}{l}\text { TAC } \\
\text { (Tyr) }\end{array}$ & $\begin{array}{l}\text { ACC } \\
\text { (Thr) }\end{array}$ & SYT & & $560-563$ & Dicromata \\
\hline & $\mathrm{F}(1)$ & TCT (Ser) & $\begin{array}{l}\text { TAC } \\
\text { (Tyr) }\end{array}$ & $\begin{array}{l}\text { ACC } \\
\text { (Thr) }\end{array}$ & SYT & & $560-563$ & Dicromata \\
\hline \multirow{2}{*}{$\begin{array}{l}\text { Lagothrix } \\
\text { lagotricha }\end{array}$} & M & TCT (Ser) & $\begin{array}{l}\text { TAC } \\
\text { (Tyr) }\end{array}$ & $\begin{array}{l}\text { ACC } \\
\text { (Thr) }\end{array}$ & SYT & & $560-563$ & Dicromata \\
\hline & $\mathrm{F}$ & $\begin{array}{l}\text { TCT/GCT } \\
\text { (Ser/Ala) }\end{array}$ & $\begin{array}{l}\text { TTC/TAC } \\
\text { (Tyr/Phe) }\end{array}$ & $\begin{array}{l}\text { ACC } \\
\text { (Thr) }\end{array}$ & ND & ND & ND & Tricromata \\
\hline \multirow{3}{*}{ Alouatta clamitans } & M (2) & $\begin{array}{c}\text { TCT/GCT } \\
\text { Ser/Ala } \\
\end{array}$ & $\begin{array}{c}\text { TAC/TTC } \\
\text { Tyr/Phe }\end{array}$ & $\begin{array}{c}\mathrm{ACC} / \mathrm{GCC} \\
\mathrm{Thr} / \mathrm{Ala}\end{array}$ & ND & ND & ND & Tricromata \\
\hline & $\mathrm{F}(2)$ & $\begin{array}{c}\text { TCT/GCT } \\
\text { Ser/Ala }\end{array}$ & $\begin{array}{c}\text { TAC/TTC } \\
\text { Tyr/Phe }\end{array}$ & $\begin{array}{c}\text { ACC/GCC } \\
\text { Thr/Ala }\end{array}$ & ND & ND & ND & Tricromata \\
\hline & M (1) & TCT (Ser) & $\begin{array}{c}\text { TAC/TTC } \\
\text { Tyr/Phe }\end{array}$ & $\begin{array}{c}\text { ACC/GCC } \\
\text { Thr/Ala }\end{array}$ & ND & ND & ND & Tricromata \\
\hline \multirow{3}{*}{ Alouatta caraya } & $\mathrm{F}(1)$ & $\begin{array}{c}\text { Ser/Ala } \\
\text { TCT/GCT }\end{array}$ & $\begin{array}{c}\text { Tyr/Phe } \\
\text { TAC/TTC }\end{array}$ & $\begin{array}{c}\text { Thr/Ala } \\
\text { ACC/GCC }\end{array}$ & ND & ND & ND & Tricromata \\
\hline & M (1) & $\begin{array}{c}\text { Ser/Ala } \\
\text { TCT/GCT }\end{array}$ & $\begin{array}{c}\text { Tyr/Phe } \\
\text { TAC/TTC }\end{array}$ & $\begin{array}{c}\text { Thr/Ala } \\
\text { ACC/GCC }\end{array}$ & ND & ND & ND & Tricromata \\
\hline & M (1) & TCT (Ser) & $\begin{array}{c}\text { Tyr/Phe } \\
\text { TAC/TTC }\end{array}$ & $\begin{array}{l}\text { ACC } \\
\text { (Thr) }\end{array}$ & ND & ND & ND & Tricromata \\
\hline \multirow{2}{*}{ Ateles belzebuth } & M (1) & $\begin{array}{l}\text { TCT } \\
\text { Ser }\end{array}$ & $\begin{array}{l}\text { TAC } \\
\text { Tyr }\end{array}$ & $\begin{array}{l}\text { ACC } \\
\text { Thr }\end{array}$ & SYT & & $560-563$ & Dicromata \\
\hline & F (3) & $\begin{array}{l}\text { TCT } \\
\text { Ser }\end{array}$ & $\begin{array}{l}\text { TAC } \\
\text { Tyr }\end{array}$ & $\begin{array}{c}\text { ACC } \\
\text { Thr }\end{array}$ & SYT & & $560-563$ & Dicromata \\
\hline
\end{tabular}

